\title{
Divergent consensuses on Arctic amplification influence on midlatitude severe winter weather
}

\author{
J. Cohen ${ }^{1,2 \star}$, X. Zhang $\mathbb{1}^{3}{ }^{3}$, J. Francis ${ }^{4}$, T. Jung ${ }^{5,6}$, R. Kwok ${ }^{7}$, J. Overland ${ }^{8}$, T. J. Ballinger ${ }^{9}$, \\ U. S. Bhatt ${ }^{3}$, H. W. Chen ${ }^{10,11}$, D. Coumou'12,13, S. Feldstein ${ }^{11}$, H. Gu14, D. Handorf5, G. Henderson ${ }^{15}{ }^{15}$, \\ M. Ionita ${ }^{5}$, M. Kretschmer ${ }^{13}$, F. Laliberte ${ }^{16}$, S. Lee ${ }^{11}$, H. W. Linderholm ${ }^{17,18}$, W. Maslowski ${ }^{19}$, Y. Peings ${ }^{20}$, \\ K. Pfeiffer ${ }^{1}$, I. Rigor ${ }^{21}$, T. Semmler ${ }^{5}$, J. Stroeve ${ }^{22}$, P. C. Taylor ${ }^{23}{ }^{23}$ S. Vavrus ${ }^{24}$, T. Vihma ${ }^{25}$, \\ S. Wang ${ }^{14}$, M. Wendisch ${ }^{26}$, Y. Wu ${ }^{27}$ and J. Yoon ${ }^{28}$
}

The Arctic has warmed more than twice as fast as the global average since the late twentieth century, a phenomenon known as Arctic amplification (AA). Recently, there have been considerable advances in understanding the physical contributions to AA, and progress has been made in understanding the mechanisms that link it to midlatitude weather variability. Observational studies overwhelmingly support that AA is contributing to winter continental cooling. Although some model experiments support the observational evidence, most modelling results show little connection between AA and severe midlatitude weather or suggest the export of excess heating from the Arctic to lower latitudes. Divergent conclusions between model and observational studies, and even intramodel studies, continue to obfuscate a clear understanding of how AA is influencing midlatitude weather.

S ince the 1990s, Arctic winter temperatures have shown an almost monotonic warming trend, at an accelerated rate relative to the rest of the globe. The period from the 1990s to the present is identified as the modern period of AA (Supplementary Fig. 1a). AA is strongest over the Arctic Ocean in autumn and winter, whereas during the summer it is weaker and shifted over land and the Greenland ice sheet ${ }^{1,2}$. The most notable sign of climate change in the Arctic is the rapidly declining sea ice extent in summer and early autumn ${ }^{3}$ in response to various reinforcing feedbacks ${ }^{4-6}$.

Over the same period, land temperatures for eastern North America, and especially eastern Eurasia, in winter have exhibited almost no warming, and indeed cooled from 2000-2013, followed by more variable winters. The recent midlatitude winter cooling period has coincided with an increase in severe winter weather events $^{2,7-9}$.

The rapid warming of the Arctic coupled with cooling or lack of warming in the midlatitudes has resulted in the diverging of Arctic and midlatitude temperature trends (Supplementary Fig. 1b). The pattern of a warm Arctic and cold continents/Eurasia (WACC/E) is the strongest observational evidence that some unaccounted-for mechanism has been offsetting greenhouse-gas-forced warming over the Northern Hemisphere (NH) midlatitudes ${ }^{10-13}$.

Theories proposed for the midlatitude winter cooling include internal variability and tropical forcing but also a new idea-AA. Over a decade ago, it was proposed that Arctic warming (1988/89 to 2007/08) and associated changes in boundary forcing, including Arctic sea ice melt and increasing extent of autumn snow cover, influence midlatitude weather through a stratospheric pathway that favours cold temperatures across the midlatitudes ${ }^{14,15}$. A composite of the temperature anomalies of the 11 subsequent winters (2009-2019; winter defined here as the months January-March) shows a similar pattern of variability, suggesting that the same physical mechanism is responsible for the WACC pattern observed in 1989-2008 and 2009-2019 (Supplementary Fig. 2). However, some differences between the two periods are noted and discussed in the Supplementary Information and in Supplementary Fig. 3. The WACE pattern was also detected during the previous AA period in the 1930s-1940s, which provides further observational support that winter continental cooling may be a forced response to $\mathrm{AA}^{16}$.

The resiliency of midlatitude winter weather was not projected by climate models ${ }^{17}$, fanning climate change scepticism, which can impede the implementation of mitigation and adaptation policies. Therefore, linking accelerated Arctic warming or AA to increased midlatitude severe winter weather is societally relevant and important, as it would assist the public and private sectors to prepare for adverse weather both in the short and long term.

Yet the challenge of demonstrating a linkage between AA and severe winter weather is daunting, given differing observational analysis methods and the large spread in modelled responses (see Supplementary Information and Supplementary Fig. 4 for a

\footnotetext{
'Atmospheric and Environmental Research Inc., Lexington, MA, USA. ${ }^{2}$ Massachusetts Institute of Technology, Cambridge, MA, USA. ${ }^{3}$ University of Alaska Fairbanks, Fairbanks, AK, USA. ${ }^{4}$ Woods Hole Research Center, Falmouth, MA, USA. ${ }^{5}$ Alfred Wegener Institute, Helmholtz Centre for Polar and Marine Research, Bremerhaven, Germany. ${ }^{6}$ University of Bremen, Bremen, Germany. ${ }^{7}$ Jet Propulsion Laboratory, Pasadena, CA, USA. ${ }^{8}$ NOAA/PMEL, Seattle, WA, USA. 'Department of Geography, Texas State University, San Marcos, TX, USA. ${ }^{10}$ Lund University, Lund, Sweden. "Pennsylvania State University, State College, PA, USA. ${ }^{12}$ Potsdam Institute for Climate Impact Research, Potsdam, Germany. ${ }^{13}$ Vrije Universiteit Amsterdam, Amsterdam, the Netherlands. ${ }^{14}$ Utah Climate Center/Department of Plants, Soils and Climate, Utah State University, Logan, UT, USA. ${ }^{15}$ United States Naval Academy, Annapolis, MD, USA. ${ }^{16}$ Environment and Climate Change Canada, Gatineau, Quebec, Canada. ${ }^{17}$ University of Gothenburg, Gothenburg, Sweden. ${ }^{18}$ University of Cambridge, Cambridge, UK. ${ }^{19}$ Naval Postgraduate School, Monterey, CA, USA. ${ }^{20}$ University of California, Irvine, CA, USA. ${ }^{2}$ University of Washington, Seattle, WA, USA. ${ }^{22}$ University College London, London, UK. ${ }^{23}$ NASA Langley Research Center, Hampton, VA, USA. ${ }^{24}$ University of Wisconsin, Madison, WI, USA. ${ }^{25}$ Finnish Meteorological Institute, Helsinki, Finland. ${ }^{26}$ University of Leipzig, Leipzig, Germany. ${ }^{27}$ Lamont-Doherty Earth Observatory, Columbia University, Palisades, NY, USA. ${ }^{28}$ Gwangju Institute of Science and Technology, Gwangju, South Korea. *e-mail: jcohen@aer.com
} 


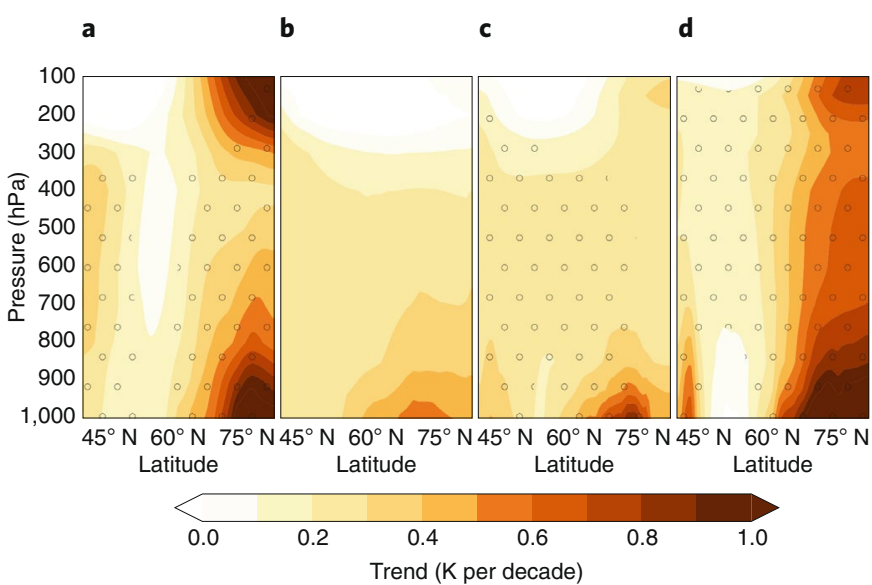

Fig. 1 | Observed and ensemble mean temperature trends show large discrepancies in winter. a, Winter (December, January, February: DJF) and zonal-mean air-temperature trends from December 1980 to February 2019 for the average of MERRA-2, ERA5, JRA-55 and CFSR reanalysis products for DJF. b, Same as a but for the CMIP5 multimodel ensemble mean historical simulation through 2004 and RCP8.5 simulation thereafter. c, Same as a, but for the AMIP multimodel mean. $\mathbf{d}$, Same as $\mathbf{c}$ but for the AMIP ensemble member that best matches the reanalysis mean based on pattern correlation. Stippling indicates significant trends with $P<0.05$ after the correction for false discovery rate was applied ${ }^{135}$.

tabulation of observational and modelling studies). Simple causality statements for a general audience are not yet defendable. And despite a flurry of research and advances in the mechanisms linking AA to midlatitude weather, the topic remains contentious.

In this Review, we focus on winter weather. For a brief discussion on AA and extreme weather, see Supplementary Information. A separate review on summer mechanisms has recently been published ${ }^{18}$.

\section{The character of Arctic amplification}

$\mathrm{AA}$ is evident in the zonal-mean winter air-temperature trends for the NH and Arctic between 1980-2019, from the surface to the upper atmosphere (Fig. 1; averaged in four reanalysis datasets, henceforth known as 'observations' in this Review). Statistically significant warming extends throughout the troposphere but is strongest near the surface, with a second maximum in the upper troposphere and stratosphere (Fig. 1a). This winter polar stratosphere warming trend is also evident in radiosonde data ${ }^{19}$. The Arctic warming ensemble-mean simulated in the Coupled Model Intercomparison Project-5 (CMIP5) is shifted south, and lacks the magnitude and vertical extent of the observations. Also, the second warming maximum in the upper troposphere and stratosphere is absent in CMIP5 compared with the observations (Fig. 1b). The shallower simulated warming could be related to coarse vertical resolution $^{20}$ or an Arctic temperature inversion that is too strong ${ }^{21}$, which would inhibit the vertical distribution of surface warming.

Besides coupled models, we also analysed the vertical distribution of temperature trends in the Atmospheric Model Intercomparison Project (AMIP) forced with observed sea surface temperatures (SSTs) and sea ice. The results are similar to those of CMIP5, with relatively shallow and southward-shifted Arctic warming and a mostly absent secondary maximum in the lower stratosphere (Fig. 1c and Supplementary Fig. 5). Further analysis of individual ensemble members reveals that several members closely match the distribution of observed temperature trends, with deeper Arctic warming in the lower- to mid-troposphere and a secondary maximum in the stratosphere (Supplementary Fig. 6); the individual ensemble member that best matches the observations is shown in Fig. 1d.
The large ensemble spread suggests that simulated and observed differences could be due to natural variability and therefore the observed temperature trends do not necessarily represent a forced response to AA.

\section{Arctic amplification mechanisms}

Understanding of contributors to AA has evolved considerably in the past decade, emphasizing that a suite of mechanisms is responsible for the enhanced sensitivity of the Arctic ${ }^{6,22,23}$. These mechanisms can be divided into local and remote forcings (summarized in Fig. 2). The local forcings include snow, sea ice albedo, cloud and ice insulation feedbacks, which are typically considered the triggers in the causal chain leading to $\mathrm{AA}^{3,24,25}$. Remote forcing mechanisms involve atmospheric and ocean heat and atmospheric moisture transport from the midlatitudes and tropics into the Arctic ${ }^{26,27}$. Recent studies argue that remote mechanisms have accelerated sea ice disappearance during both winter ${ }^{28-31}$ and summer ${ }^{28,29,32,33}$ and are important contributors to AA. Thus, local and remote mechanisms may interact and amplify one another ${ }^{24}$. For instance, tropical convection-forced warming through the transport of heat and moisture may be further amplified by local feedback processes, such as increased clouds.

Perhaps the best-known Arctic feedback is sea ice albedo ${ }^{34}$, caused by the stark albedo difference between ice-free ocean and snow-covered sea ice surfaces (about $7 \%$ and about $80 \%$ reflectance, respectively). The long-term darkening of the Arctic surface resulting from sea ice loss has been observationally confirmed, indicating a mean surface albedo reduction from 0.52 to 0.48 since $1979^{35}$. The increase in vegetation over Arctic land further contributes to a darkening surface at high latitudes ${ }^{36}$. Additionally, rapid continental snow cover loss in spring lowers the surface albedo and allows the underlying soil to dry out more rapidly, favouring earlier and more intense warming of high-latitude land areas $^{37}$.

During winter, insulation by sea ice wanes during $\mathrm{AA}^{25}$. The anomalously low extent of summer sea ice exposes darker ocean water to sunlight, allowing greater absorption of solar radiation, thus warming the Arctic upper-ocean mixing-layer and promoting anomalous latent and sensible heat fluxes in the autumn. Subsequently, this process delays sea ice-growth in the autumn/winter, allowing for warmer and moister Arctic air masses that further contribute to $\mathrm{AA}^{38-40}$. Analysis of surface turbulent flux trends indicate enhanced fluxes from the ocean to the atmosphere in the Chukchi and Kara Seas in recent years ${ }^{39,41-43}$.

The sea ice albedo feedback is not the only important mechanism contributing to $\mathrm{AA}^{44}$. A new consideration of equal or possibly more importance is the local feedback related to the impact of low-level mixed-phase clouds ${ }^{45}$. The net radiative effect of Arctic clouds is to warm the surface via enhanced downward longwave radiation for much of the year (predominantly during the polar night in winter), except in June and July when the reflection of solar radiation by clouds may dominate, cooling the surface ${ }^{46,47}$. The impact of clouds is further complicated by the seasonal evolution of surface albedo, including the summer sea ice melt and production of melt ponds ${ }^{48}$. CMIP5 model results disagree on whether Arctic cloud changes dampen or amplify $\mathrm{AA}^{4,47}$.

Emerging evidence suggests that downward longwave radiation from anomalous cloud cover during winter can hinder the growth of sea ice ${ }^{49-55}$. In addition, analysis of CMIP5 models indicates that changes in downward longwave radiation flux from a cloudless atmosphere, rather than the sea ice albedo feedback, is the largest contributing factor to simulated $\mathrm{AA}^{47}$. Observations indicate that trends in downward longwave radiation are positive almost everywhere, owing to increased atmospheric water vapour over the Arctic Ocean for all seasons ${ }^{2}$. Additional discussion on AA mechanisms is included in the Supplementary Information.

Despite the robust signal of AA, knowledge of the mechanisms remains incomplete. The roles of meridional (poleward) 


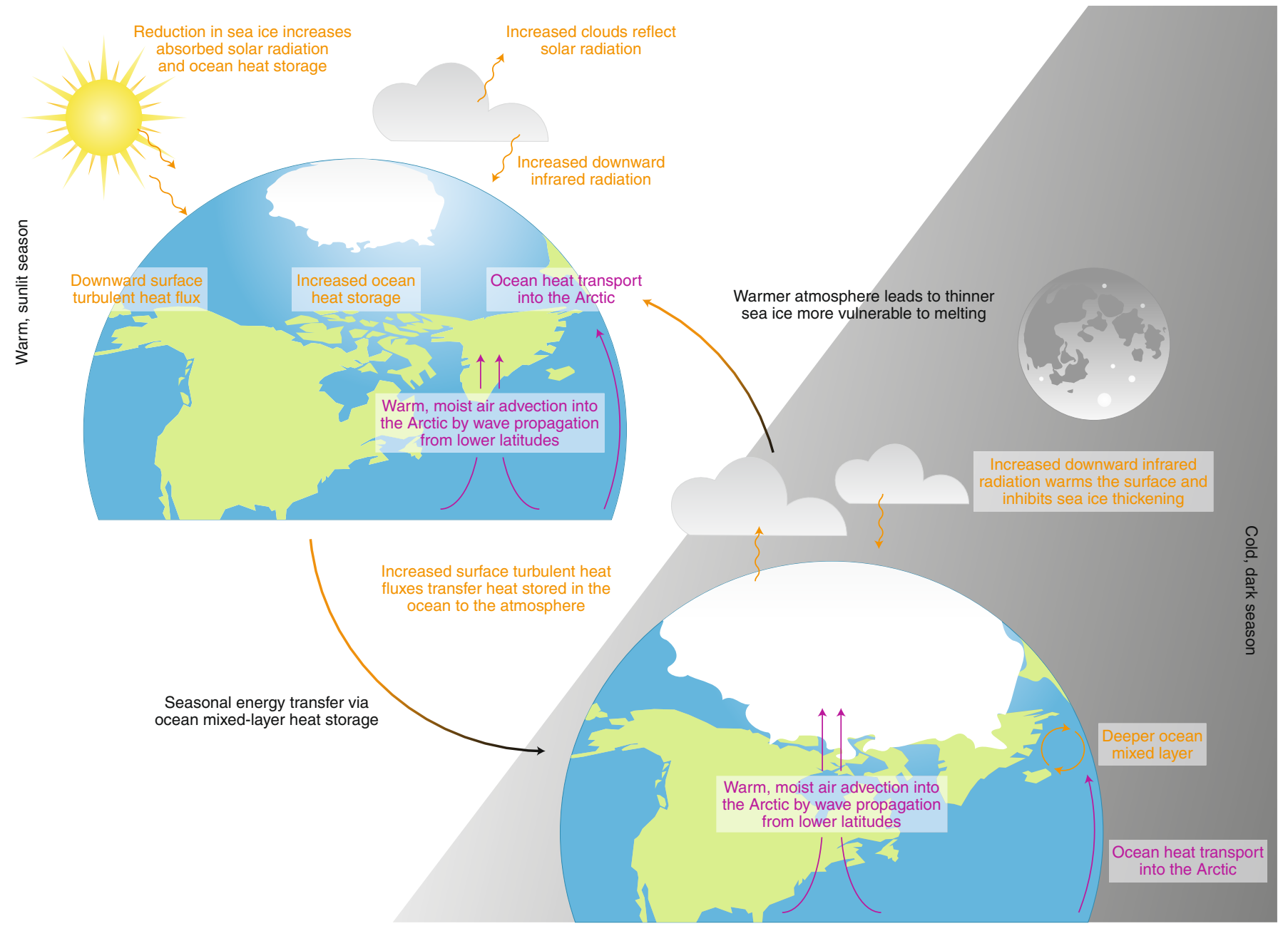

Fig. 2 | Mechanisms of Arctic amplification are complicated. This schematic diagram illustrates the important processes and energy flows influencing Arctic amplification. Local processes, such as sea ice albedo feedbacks, changes in surface turbulent fluxes, clouds, ocean heat storage and ocean mixedlayer change, are indicated in orange. Remote processes, such as atmosphere and ocean heat transport, are indicated in purple. An important aspect of Arctic amplification is the seasonal transfer of energy from the sunlit to the dark season, denoted by the graduated arrow (orange-black).

atmospheric heat and moisture transport, oceanic heat transport from midlatitudes into the Arctic ${ }^{28,29}$ and particularly the importance of the episodic deposition of heat and moisture at the synoptic scale are just beginning to be understood ${ }^{40,56-58}$. A more comprehensive understanding of the chain of events leading to AA and the individual contributions of each process is needed, as the magnitude and mechanisms of AA fundamentally influence the character and likelihood of Arctic and midlatitude connections ${ }^{59}$.

\section{Arctic midlatitude linkages}

Extensive new sea-ice-free areas in autumn and thinner sea ice in early winter months allow for greater heating of the overlying atmosphere, which represents a possible mechanism linking AA to midlatitude weather. Preferential warming of the Arctic atmospheric column leads to increased geopotential height thickness and a reduced meridional gradient as described by the geopotential tendency equation ${ }^{60}$, which can slow the polar jet stream. It has been theorized that weakened zonal winds increases the likelihood of slower and more amplified Rossby waves, enhancing the possibility of blocking situations ${ }^{1}$ and meridional transport of air masses associated with extremes. However, this idea has encountered scepticism ${ }^{61,62}$.

A research challenge is to identify and understand possible links of thermal heating from Arctic sources to midlatitude weather. Amplified warming does increase the potential for Arctic change to influence weather outside the region, especially if it increases the likelihood of high-latitude blocking. Blocking results from waves breaking within the background flow, which makes weather systems move more slowly or even become stationary ${ }^{63,64}$. Like boulders blocking a river, once an atmospheric block forms, its impacts are felt both upstream and downstream of the block. Moreover, blocking events have been implicated as precursors for sudden stratospheric warmings ${ }^{65-67}$, which in turn influence winter weather for up to two months $s^{68-70}$.

Below-normal temperatures during the winter months over Europe and North America are associated with blocking anticyclones over high-latitude areas of northwestern Eurasia and Greenland, respectively ${ }^{3,71-76}$. In addition to cold temperatures, recent observations show that high-latitude blocking is related to more frequent heavy snowfalls in the eastern United States ${ }^{74}$, and an index of disruptive northeastern US snowfalls shows that over the most recent decade the population centres of this region have been adversely impacted by snowstorms three times as often as in any previous decade (Supplementary Fig. 7).

Midlatitude weather is highly complex, strongly steered by nonlinear jetstream dynamics including the impact of anomalous transient storm systems on the growth and phasing of planetary waves $^{77}$, the onset and maintenance of blocking, and the strength 
and location of the Siberian $\mathrm{High}^{78}$. Further complicating attribution of weather events is that possible signals, including Arctic forcing, are masked by internal variability ${ }^{79}$ creating signal intermittency ${ }^{78,80}$. Arctic-midlatitude linkages may also be sensitive to decadal variability in global SSTs ${ }^{81-83}$. The complexity of midlatitude weather and the dependence on the background flow challenges the ability to link AA to midlatitude weather, especially episodic events such as cold air outbreaks and heavy snowfalls.

\section{Hemisphere-wide response to AA}

The exchange of heat from the Arctic Ocean to the atmosphere during delayed re-freezing in autumn and reduced vertical stability can intensify storm systems over the Arctic ${ }^{84-86}$. The nonlinear interaction between storm systems and planetary-scale waves contributes to changes in the atmospheric circulation, which can constructively or destructively interfere with the large climatological standing waves; enhancement (destruction) of these waves can increase (decrease) upward propagation of energy in early to mid-winter that weakens (strengthens) the stratospheric polar vortex ${ }^{77,87,88}$. The tropospheric response to either a weakened or strengthened polar vortex is hemispheric in scale and most closely resembles the negative or positive Arctic Oscillation (AO), respectively ${ }^{15,89,90}$.

The earliest modelling studies demonstrated that the complete melt of Arctic sea ice forced a negative AO temperature response $e^{91,92}$. Follow-up studies reaffirmed that regionally reduced sea ice extent predominately forced a negative AO circulation response with increased sea level pressure over the Arctic and decreased sea level pressure over the midlatitudes in winter ${ }^{93-95}$.

However, a numerical study published in 2005, in which the Hadley Centre Atmosphere-3 (HadAM3) global climate model (GCM) was forced with pan-Arctic sea ice variability, found no significant relationship between differences in sea-ice concentration and the $\mathrm{AO}^{96}$. Following this, a number of large ensemble modelling studies have come to the same conclusion-that is, there is little modelling evidence of an atmospheric response to the pan-Arctic sea ice trend ${ }^{97-99}$. One possible explanation for the discrepancy in the hemispheric response between regionally and pan-Arctic-forced sea ice anomalies is that simultaneous forcing from different regions negate each other ${ }^{51,100,101}$. Although Scandinavian/Ural blocking has been shown to weaken the polar vortex, Eastern Asia/Northwest Pacific blocking has been shown to strengthen $\mathrm{it}^{102}$. The response of the polar vortex to sea ice loss is dependent on the location of the ensuant blocking, which may help to interpret the diverse response to sea ice loss in models.

\section{Regional response of AA}

Previous reviews have focused on the influence of AA on midlatitude weather related to the hemispheric response projected onto the AO pattern of variability ${ }^{7,9}$. However, research now suggests that regional anomalies in sea ice or temperature can force regional responses in midlatitude weather. These have focused on the relationship between sea ice loss and/or warming in the Barents-Kara Seas region with cold temperatures across Siberia and Central Asia for the recent period (that is, the WACE pattern $)^{71,103-107}$. A link between sea ice melt and/or warming over the Chukchi Sea and central North American cold temperatures ${ }^{12,80}$ and sea ice melt and/or warming in and around Greenland and eastern North American and Northern European temperatures have also been suggested $^{74,108,109}$. Additional detail on the regional response to AA is provided in the Supplementary Information.

Although there is a lack of consensus between observational and modelling studies on the hemispheric response to sea ice loss, there is possibly more agreement on the downstream regional response to localized Arctic sea ice loss and/or warming. Analysis of recent Arctic sea ice concentration trends shows three main regions of sea ice retreat in winter: Barents-Kara Seas, Chukchi-Bering Seas and around Greenland (see Supplementary Fig. 8). In Fig. 3, we plot the temperature anomalies associated with above-normal winter temperatures regionally in the Arctic, in both the observations and the Hadley Centre Global Environmental Model-2 (HadGEM2 ${ }^{51}$ ). Regional warming in the Barents-Kara Seas is linked to below normal temperatures across Central and East Asia. Regional warming in the Canadian Archipelagos-Baffin Bay and Greenland Seas is associated with below-normal temperatures across Northern and Central Europe, Siberia and, to a lesser degree, eastern North America. Finally, regional warming in the Chukchi-Bering Seas is related to below normal temperatures across Central and Eastern North America. Somewhat consistent results were found when the HadGEM2 was forced with regional sea ice loss ${ }^{51}$ (Fig. 3) - sea ice loss in the Barents-Kara Seas resulted in weak cooling across Eurasia, sea ice loss in the Canadian Archipelagos-Baffin Bay and Greenland Seas resulted in cooling across Europe, parts of Canada and the Eastern United States, and sea ice loss in the BeaufortChukchi Seas resulted in cooling in parts of North America.

However, even though the regression of pan-Arctic warmth with hemispheric temperatures yields midlatitude cooling in both the observations and models, pan-Arctic sea ice loss does not force a weakened polar vortex in the models $s^{51,100}$, and cooling across the midlatitudes is nearly absent (Fig. 3). Therefore, although models do simulate regional cooling forced by regional sea ice loss, the cumulative response to each separate region does not add linearly but rather destructively, resulting in overall warming across the continents $^{100,101}$.

In general, the cooling from the modelling experiments is weaker than that derived from observational analysis. Additionally, while simulated regional sea ice loss results in downstream localized cooling, pan-Arctic sea ice loss results in warming across the Arctic and adjacent land areas, with almost no discernible cooling ${ }^{51}$.

\section{Observational analysis versus modelling}

Based on the consideration of a large majority of observational studies, we identified a list of proposed physical processes and/ or mechanisms linking Arctic change and midlatitude weather, ordered from high to low confidence. These include: increasing geopotential thickness over the Arctic ${ }^{2,110}$; weakening of the thermal wind $^{3,111}$; modulating stratosphere-troposphere coupling ${ }^{67,89,112}$; exciting anomalous planetary waves or stationary Rossby waves in winter; changes in the atmospheric circulation and associated strengthening of the Siberian high and Aleutian low $^{28,98,113}$; altering storm tracks and behaviour of blockings ${ }^{86,114,115}$.

The dynamical pathway considered most robust involves Barents-Kara sea ice loss contributing to a northwestward expansion of the Siberian High or Ural blocking leading to cold Eurasian winters (for example, refs. ${ }^{9,106,107,116}$ ). The Barents-Kara Seas region has experienced the greatest winter sea ice loss in the Arctic (Supplementary Fig. 8). This leads to large heating of the overlying atmosphere, dilation of the geopotential heights and a weakening of the westerly wind that favours increased blocking over the BarentsKara Seas and adjacent Ural Mountains region ${ }^{107,117}$. A ridge over northwestern Eurasia with a trough over northeastern Eurasia is favourable for the direct forcing of planetary waves onto the stratosphere via enhanced vertical propagation of wave energy $y^{88,89,118}$. This can lead to wave breaking and disruption of the stratospheric polar vortex ${ }^{119}$. Considerable disruption of the polar vortex is then followed by a negative AO response and widespread cold temperatures across the NH midlatitude continents ${ }^{69,112}$ but with a focus across $\mathrm{Asia}^{70}$.

The simulated response to Arctic sea ice loss has spanned a wide spectrum from no response to warming and cooling of the midlatitudes. Early modelling studies found that low sea ice, either pan-Arctic or east of Greenland and extending into the BarentsKara seas, forced cold temperatures across the $\mathrm{NH}$ continents similar 


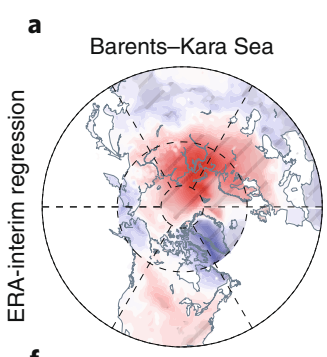

,

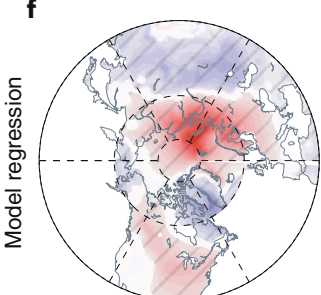

k

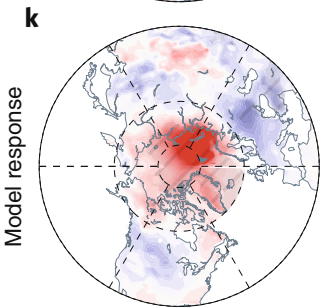

b

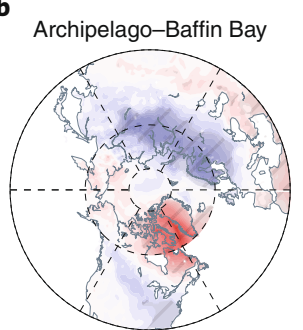

g

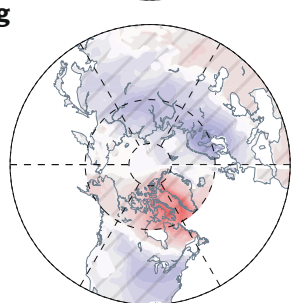

I

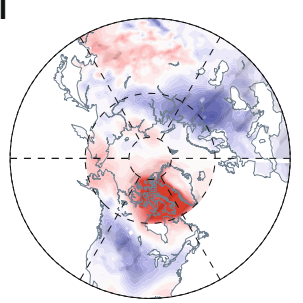

c

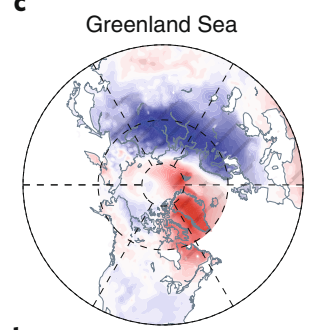

h

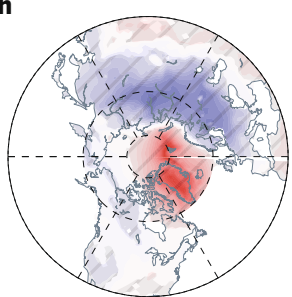

m

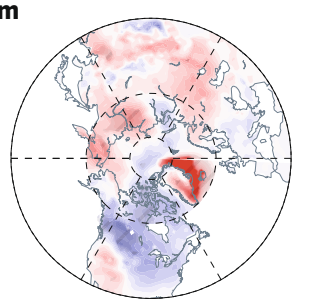

d

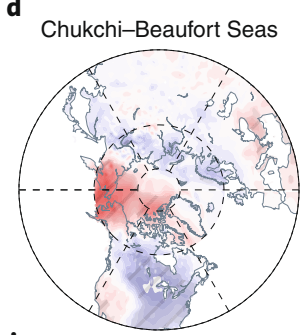

i
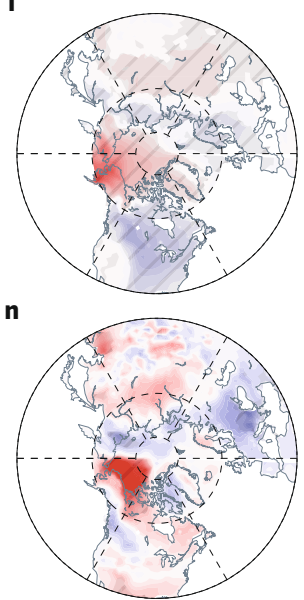

e

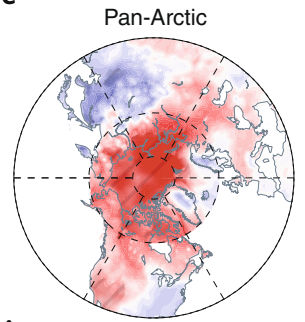

j

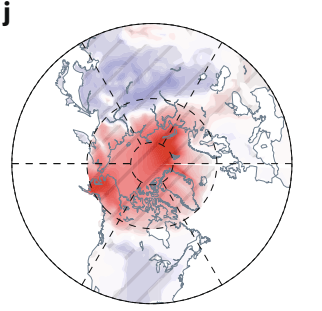

o

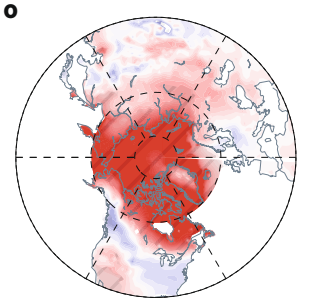

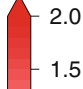

1.0

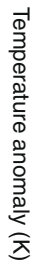

Fig. 3 | Observed and simulated winter temperature relationships to Arctic warming share similarities regionally. a-e, Observed NH near-surface air-temperature anomalies for all days when 850-hPa temperature anomalies were between 0.5 and 3.0 standard deviations above the climatological average for all winters (DJF) 1950-2019 in (a) Barents-Kara Sea, (b) Canadian Archipelago-Baffin Bay, (c) Greenland Sea, (d) Chukchi-Beaufort Seas and (e) Pan-Arctic regressed onto NH surface temperatures. Anomalies are calculated relative to climatological averages from 1981 to 2010 . $\mathbf{f}-\mathbf{j}$, Same as for a-e but for atmospheric output from the ensemble-mean HadGEM2 GCM. k-o, October-to-March mean near-surface air-temperature responses in HadGEM2 model simulations from ref. ${ }^{51}$ to observed sea-ice loss in the (k) Barents-Kara Sea, (I) Canadian Archipelago-Baffin Bay, (m) Greenland Sea, (n) Chukchi-Beaufort Seas and (o) Pan-Arctic. Hatching denotes statistically significant response at the $95 \%$ confidence level using the Student's $t$-test. ERA-Interim used for observational data.

to the negative AO temperature pattern ${ }^{91-95}$. However, since then, modelling studies have supported the entire range of atmospheric response, including cold continents ${ }^{12,69,71,105,106,112,116,120,121}$, a disrupted stratospheric polar vortex comparable to observed ${ }^{69,112,118,121}$ and weaker and/or delayed relative to observed ${ }^{51,100}$, a negative $\mathrm{AO}^{118,122}$, a positive $\mathrm{AO}^{123,124}$ with mild continental temperatures ${ }^{125}$ and finally no robust impact on midlatitude weather ${ }^{97-99,126}$.

Still, despite the wide spectrum of modelled responses, in most modelling investigations, especially those involving large ensembles, the atmospheric response to low sea ice forcing is small relative to the internal variability and does not include cold winters across the NH midlatitude continents. Therefore, based on these studies, observed cooling is attributed to natural variability ${ }^{12,97-99,124,126}$. However, some of the differences in observed and modelled polar vortex behaviour may be due to the fact that most GCMs are 'low-top' models and only poorly resolve the stratosphere and stratosphere-troposphere coupling mechanisms ${ }^{88,127}$. Some recent 'high-top' climate models with improved stratospheric variability support an atmospheric response to sea ice loss more consistent with observational analysis ${ }^{100,112,121}$.

\section{Recent NH winter temperature trends}

Temperature anomalies for the midlatitude continents (all land grid points $30^{\circ}-60^{\circ} \mathrm{N}$, for December to March from 1988/89 through 2018/19 from observations and the corresponding predicted temperature anomalies from the North American Multi Model Ensemble $\left(\mathrm{NMME}^{128}\right)$ initialized with atmospheric and oceanic conditions including sea ice on 1 November for each year) display little organization other than a warm temperature bias (Fig. 4a). A fairly wide scatter of predicted and observed temperature anomalies exists over the period, which could be considered representative of the noisy nature of midlatitude weather and/or the lack of consensus in Arctic forcing.

Comparison of observations and the model forecast midlatitude continent temperature anomalies separately, however, reveals some systematic patterns (Fig. 4b). The observed temperature anomalies are always on the cold extreme of the envelope of model forecasts, and many observed winters are even colder than the most extreme cold ensemble member. When the observed values are plotted with the ensemble mean of the model forecasts only, a clear dichotomy appears (Fig. 4c) - the observed value is colder than the ensemble mean in the era of AA without exception. The models predict that the midlatitudes should be warming at a rate nearly identical to the warming for the entire $\mathrm{NH}$ of $+0.039^{\circ} \mathrm{C}$ per year. In contrast, the observations show that temperatures across the midlatitude continents have remained nearly constant and the model-simulated rate of warming is diverging from the observed rate by about $+0.38^{\circ} \mathrm{C}$ per year. Similarly, trend lines diverge in the Arctic, with the simulated rate of Arctic warming only half of that observed (Fig. 4d). In contrast, comparison of the tropics, midlatitude oceans (Supplementary Fig. 9) and even $\mathrm{NH}$ land and ocean temperature for both the observations and the model forecasts shows good agreement between the model-predicted and observed hemispheric winter temperatures trends (Fig. 4d), despite the divergence in midlatitude land and Arctic winter temperatures (Fig. 4c). Finally, in the Supplementary Information and Supplementary Fig. 10, we present summer temperature trends where the observed and simulated midlatitude temperature trends are comparable. 


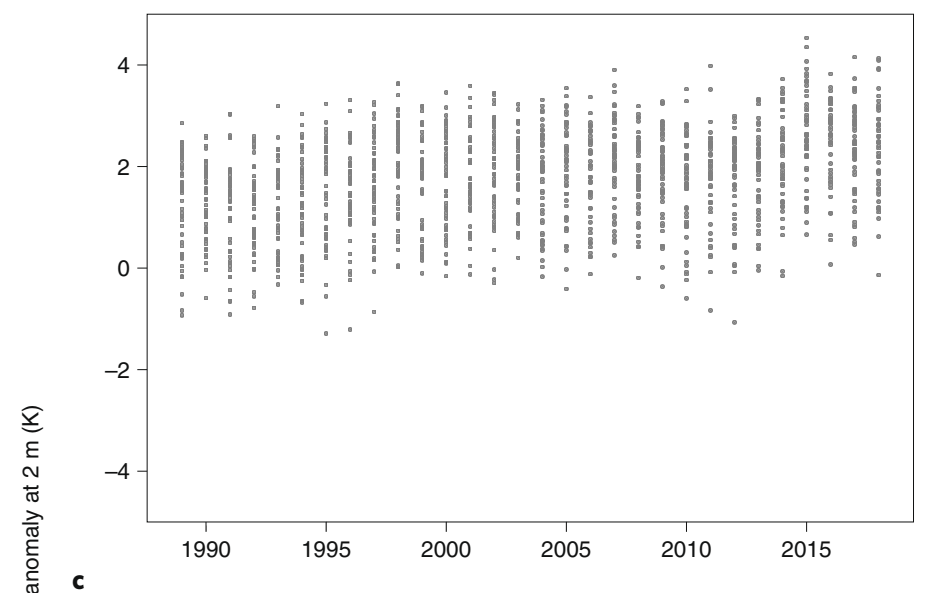

C

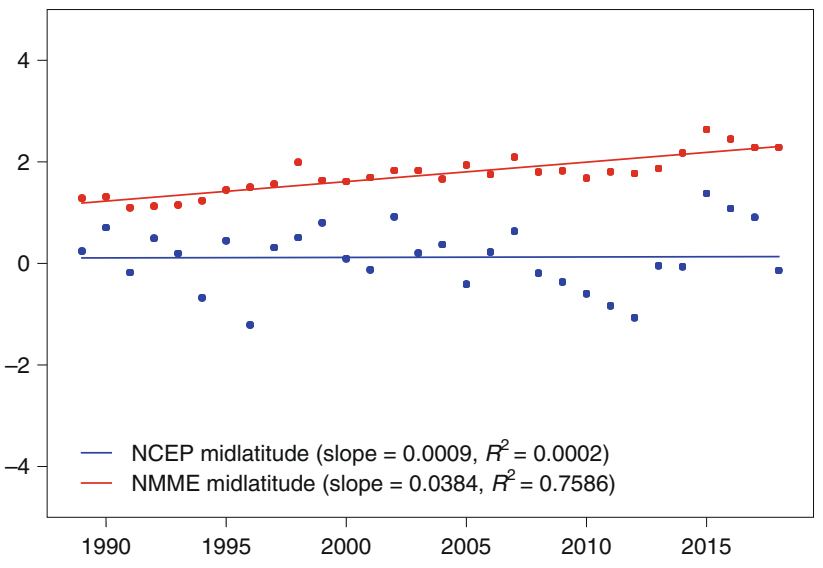

b
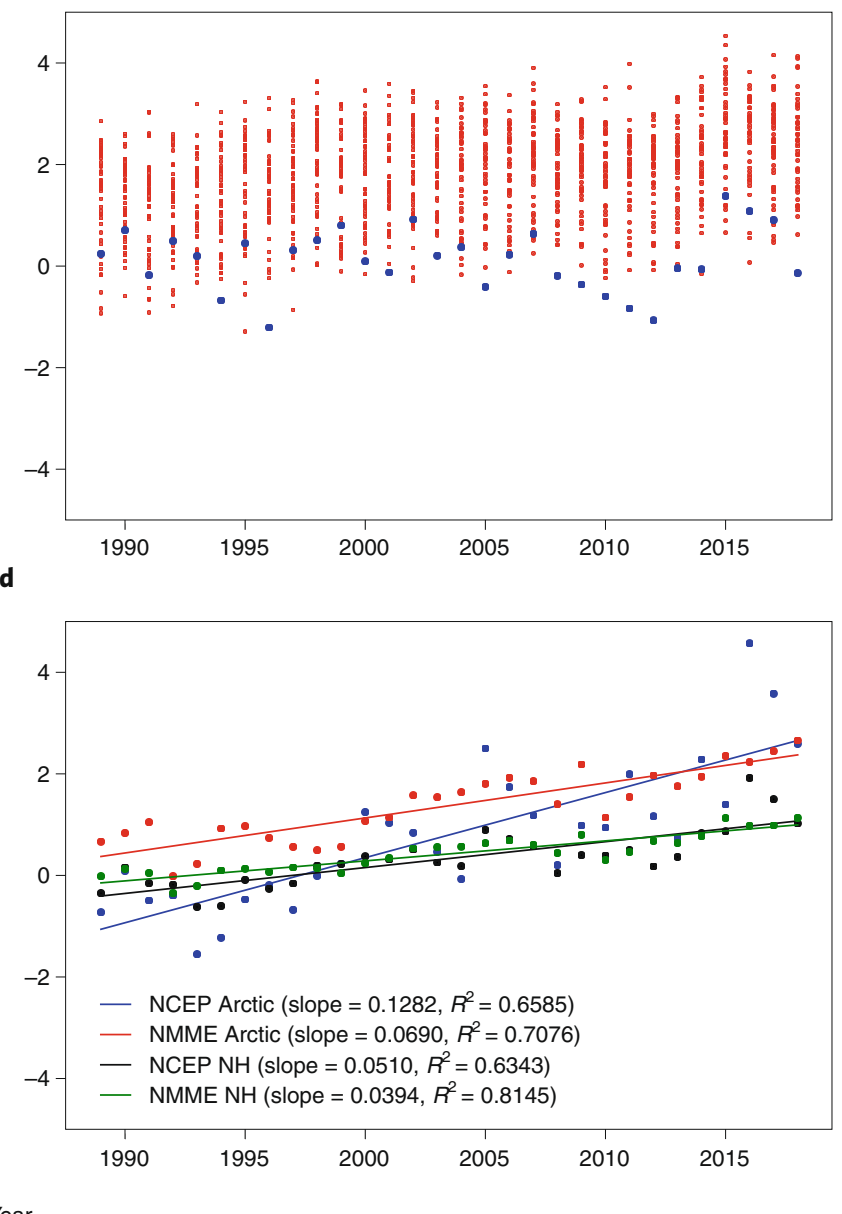

Year

Fig. 4 | Observed and simulated midlatitude winter temperature trends are diverging. a, Reanalysis and hindcasted/predicted NMME individual ensemble members for NH midlatitude continental 2-metre (above the surface) temperature anomalies. b, Same as a but reanalysis (blue) and NMME (red). c, Reanalysis (blue) and hindcasted/predicted NMME ensemble mean (red) NH midlatitude continental temperature anomalies. Also included is the linear trend line for each dataset. d, Reanalysis (black) and hindcasted/predicted NMME ensemble mean (green) NH temperature anomalies and reanalysis (blue) and hindcasted/predicted NMME ensemble mean (red) Arctic temperature anomalies and linear trends. All temperature anomalies are for December, January, February and March from 1988/89 through 2018/2019. Anomalies are calculated relative to climatology from reanalysis 1981-2010 and from NMME 1982-2010 winter mean respectively. Variance $\left(R^{2}\right)$ included for all trend lines. All trends except the NCEP NH midlatitude land regions are statistically significant at the $>99 \%$ confidence level. There is a cold bias in the climatology of the NMME models extratropical atmosphere compared with the observations. In Supplementary Fig. 10, we show the NMME temperature anomalies relative to the NMME climatology.

These plots represent a new paradigm of two distinct and divergent camps on the influence of AA on midlatitude winter weather. Although the $\mathrm{NH}$ is warming in the GCMs at a rate comparable to the observed warming, the distribution of that heating is clearly different in the era of AA. The models suggest that during AA, anomalous winter warming is more equitably distributed between the Arctic and the midlatitudes so that both regions are warming at a rate comparable to or faster than the hemispheric average. In contrast, the observed temperature trends coupled with observational studies suggest that AA favours the increase of the meridional exchange of air masses between the Arctic and the midlatitudes, resulting in the $\mathrm{NH}$ midlatitude continents cooling relative to the whole $\mathrm{NH}$ as Arctic warming accelerates. This asymmetric distribution of observed $\mathrm{NH}$ warming is consistent with the surface temperature anomaly pattern following polar vortex disruptions ${ }^{90}$.

Empirical studies have highlighted that the excessive Arctic heat is distributed vertically through the lower- and mid-troposphere rather than horizontally (Fig. 1). The vertical distribution of the heat in the Arctic that extends to the mid-troposphere supports high-latitude blocking that further favours a poleward transport of heat from lower latitudes into the polar stratosphere that is conducive to disrupting the polar vortex. Following polar vortex disruptions, Arctic air is displaced into the midlatitudes, resulting in either cooling or a delay in the warming rate of the midlatitudes relative to the remainder of the $\mathrm{NH}$. In contrast, model-simulated AA is relatively shallow but horizontally extensive (Fig. 1), which is only favourable for a weak disruption of the polar vortex that does not significantly cool the midlatitudes. A simplified explanation of the WACC pattern in the era of AA based on the majority of observational analysis and model data is provided in Boxes 1 and 2.

\section{Conclusions}

Improved understanding and parsing of the influence of Arctic, global SSTs and internal variability on midlatitude weather provides a clear pathway for improving subseasonal to seasonal weather outlooks that will aid policymakers in decisions and activities related to climate change. Projections have been for winters to become increasingly mild, with less frequent snowfalls. However, 


\section{Box 1 | Observational studies}

Observational analyses support that AA, and in particular sea ice loss, can influence midlatitude winter weather through a stratospheric pathway. Climatology favours a strong polar vortex supported by cold air over the Arctic and milder air at lower latitudes. This temperature distribution forces low geopotential heights over the Arctic and higher heights in the midlatitudes (left panel of the figure). In recent decades, this climatologically favoured configuration of the polar vortex has become increasingly perturbed ${ }^{15,70,88,116}$. Although Arctic warming is strongest at the surface (see Fig. 1 in the text), it extends throughout the midtroposphere. In addition, the sea ice loss and associated warming is not uniform across the Arctic, but rather regionally focused. Concentration of Arctic warming in the Barents-Kara Seas dilates geopotential heights over northwestern Eurasia, leading to more frequent high-latitude Scandinavian/Ural blocking that is favourable for the excitation of vertically propagating energy associated with large-scale planetary waves ${ }^{9,67,69,88}$. The increased vertical propagation of energy is coupled with more frequent intrusions of warm air from lower latitudes, depositing heat in the polar stratosphere, which causes a second maximum of Arctic warming where the polar vortex normally resides. Warming throughout the atmospheric column dilates the geopotential heights sufficiently to reverse the normal Equator-pole geopotential height gradient, resulting in cold air previously trapped near the pole to be displaced to the midlatitudes. As air flows southward away from the North Pole towards the Equator, the air is deflected to the west by the Coriolis force, forming an easterly wind around the North Pole. The redistribution of air masses that happens first in the stratosphere is then replicated through the troposphere to the surface. This completes the reversal of the $\mathrm{NH}$ circulation pattern with relatively warm temperatures and high geopotential heights over the Arctic and lower heights in the midlatitudes accompanied by more frequent cold air outbreaks to the midlatitudes (right panel).

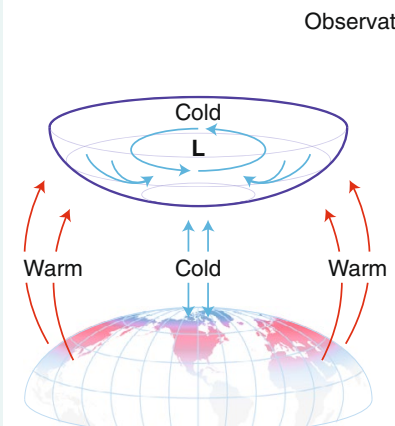

Pre-Arctic amplification

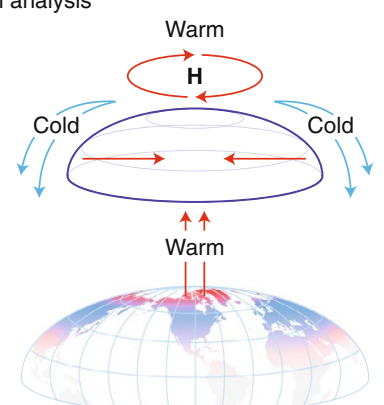

Warm Arctic/weak polar vortex
Temperature anomaly $(\mathrm{K})$

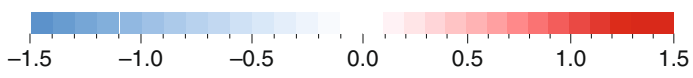

How Arctic amplification influences midlatitude weather through the polar vortex, based on observational analysis.

\section{Box 2 | Modelling data}

The large-scale hemispheric circulation is similar in model simulations to the observations during the pre-AA period, with cold air over the Arctic, milder air over the midlatitudes and subtropics and the stratosphere dominated by a strong polar vortex with higher geopotential heights at lower latitudes (left panel in Box 1 figure). However, in the ensuing period of AA, the excess warming generated in the Arctic due to sea ice loss and other mechanisms described above is not redistributed vertically in model simulations, but rather horizontally (Fig. 1 in the text) via advection or conduction from the Arctic to lower latitudes ${ }^{11}$. Furthermore, the CMIP5 and AMIP simulations either lack or have a relatively weak second maximum in heating in the polar stratosphere during the AA era. The simulated AA atmospheric circulation is nearly unchanged from the pre-AA period other than a weakening of the geopotential height gradient from Equator to pole, resulting in no increase in cold air outbreaks from the Arctic to the midlatitudes. Instead, cold air outbreaks are moderated, contributing to further warming of the midlatitudes (left panel). The simulated shallower Arctic heating either is insufficient in depth to force a disruption of the polar vortex or at most a polar vortex disruption of comparably weak magnitude in many modelling experiments. Therefore, any induced dynamical cooling, either due to a simulated weaker stratospheric polar vortex or a negative $\mathrm{AO}$, is overwhelmed by amplified Arctic warming and the transport of the milder Arctic air southward ${ }^{136}$. Conceptual mechanisms are derived from archived ensembles coordinated among modelling centres.

Instead, most model simulations indicate that during AA, observed colder temperatures in the midlatitudes are due to natural/internal variability or a remote forcing other than AA. As an example, changes in tropical convection transports additional heat both into the Arctic ${ }^{137}$, resulting in amplified warming, and into the polar stratosphere, leading to a more highly disrupted polar vortex and displacement of cold air southwards to lower latitudes ${ }^{138}$ (right panel).
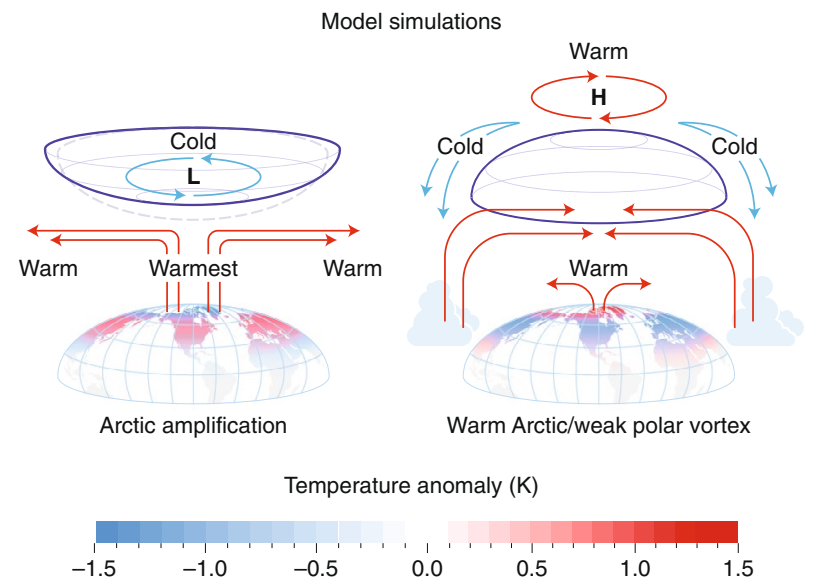

How Arctic amplification influences midlatitude weather through the polar vortex, based on numerical modelling experiments. severe winter weather persists, and in some regions, heavy snowfalls have become more, not less, frequent ${ }^{74}$. Although a growing number of studies argue that AA has contributed to more frequent severe winter weather across the $\mathrm{NH}$ continents, these are countered by others that argue differently-the influence of pan-Arctic warming is either insignificant or, alternatively, contributes to milder midlatitude winters. The divide on the influence of Arctic change has contributed to the impression that this research topic is controversial and lacking consensus ${ }^{8,129-131}$. An alternative interpretation is that the wide range of results should be expected, owing to the varying approaches to studying the problem and the complexity and intermittency of Arctic/midlatitude connections ${ }^{80,132,133}$. 
Here we have attempted to elucidate the complexity of the topic by surveying and synthesizing observational and modelling studies so far (see Supplementary Fig. 4). First, we highlight that AA is not limited to sea ice melt but rather has multiple causes, with considerable spread among climate model projections. Although true consensus on the mechanisms of Arctic/midlatitude weather linkages is lacking, a more comprehensive assessment reveals a convergence of scientific evidence and ideas. Whereas early studies focused on the hemispheric response to sea ice anomalies, more recent studies highlight the importance of regional atmospheric response to localized sea ice anomalies; model and observational studies may share common ground demonstrating those linkages. However, we conclude that most model and observational studies diverge on the hemispheric response to pan-Arctic sea ice anomalies and warming. Overwhelmingly, observational studies argue that AA forces winter cooling across the midlatitude continents, whereas most modelling experiments do not. The spatial distribution of $\mathrm{NH}$ winter warming rates in the model simulations closely aligns with expectations of AA - the warming increases with latitude, the tropics warm the least, the Arctic warms the most, and the midlatitudes fall somewhere in between and close to the $\mathrm{NH}$ average. Therefore, the conclusion of many modelling studies is that any observed midlatitude winter continental cooling trends in the twenty-first century are due to natural variability. In contrast, observed $\mathrm{NH}$ winter warming rates have been characterized by moderate warming in the tropics, amplified warming in the Arctic and almost no warming across the midlatitude continents. The conclusion of empirical studies is that the distribution of observed heating rates probably cannot be explained without including dynamical arguments related to AA.

Currently, observed and simulated $\mathrm{NH}$ midlatitude continental temperature trends are diverging. If future midlatitude winters warm while converging towards simulated trends, then the current divergence is likely to have been a result of natural variability. Alternatively, future modelling simulations may converge towards support of the observationally derived hypothesis that AA favours colder midlatitude winters. As discussed above, modelling studies with regional sea ice melt confined to the Barents-Kara Seas and a well resolved stratosphere with interactive stratospheric chemistry do simulate a weakened polar vortex and cold midlatitudes ${ }^{51,106,112,116,121}$ consistent with the observations. Precise representation of the stratosphere in models may help to resolve discrepancies between model and observational studies. A set of coordinated modelling studies is under way ${ }^{134}$ that is designed to better quantify the forced atmospheric response to sea ice loss ${ }^{113}$.

Although further research should elucidate the varying mechanisms of Arctic/midlatitude weather linkages, it remains a challenge to extricate cause-and-effect signals from the inherently chaotic climate system. The present lack of certainty may frustrate policymakers and the general public, but science often advances slowly on issues with great complexity and large variability. Regardless, this review of the state of research on connections between a rapidly melting Arctic and severe winter weather is timely, as large population centres in North America and Eurasia continue to experience severe cold, snowstorms and weather whiplash. Ongoing research will provide progress towards consensus on this scientifically and societally important topic.

\section{Online content}

Any methods, additional references, Nature Research reporting summaries, source data, extended data, supplementary information, acknowledgements, peer review information; details of author contributions and competing interests; and statements of data and code availability are available at https://doi.org/10.1038/s41558-019-0662-y.

Received: 20 July 2018; Accepted: 15 November 2019; Published online: 23 December 2019

\section{References}

1. Francis, J. A. \& Vavrus, S. J. Evidence linking Arctic amplification to extreme weather in mid-latitudes. Geophys. Res. Lett. 39, https://doi.org/10.1029/ 2012GL051000 (2012).

Influential early observational study arguing that Arctic amplification is contributing to more extreme weather in all seasons.

2. Cohen, J. et al. Arctic Change and Possible Influence on Mid-latitude Climate and Weather. US CLIVAR Report 2018-1, https://doi.org/10.5065/ D6TH8KGW (2018).

3. Stroeve, J. C. et al. Trends in Arctic sea ice extent from CMIP5, CMIP3 and observations. Geophys. Res. Lett. 39, https://doi.org/10.1029/2012GL052676 (2012).

4. Pithan, F. \& Mauritsen, T. Arctic amplification dominated by temperature feedbacks in contemporary climate models. Nat. Geosci. 7, 181-184 (2014).

5. Döscher, R., Vihma, T. \& Maksimovich, E. Recent advances in understanding the Arctic climate system state and change from a sea ice perspective: a review. Atmos. Chem. Phys. 14, 13571-13600 (2014).

6. Wendisch, M. et al. Understanding causes and effects of rapid warming in the Arctic. Eos 98, https://doi.org/10.1029/2017EO064803 (2017).

7. Vihma, T. Effects of Arctic sea ice decline on weather and climate: a review. Surv. Geophys. 35, 1175-1214 (2014).

8. Overland, J. E. et al. The melting Arctic and mid-latitude weather patterns: are they connected? J. Clim. 28, 7917-7932 (2015).

9. Cohen, J. et al. Recent Arctic amplification and extreme mid-latitude weather. Nat. Geosci. 7, 627-637 (2014).

10. Overland, J. E., Wood, K. R. \& Wang, M. Warm Arctic-cold continents: impacts of the newly open Arctic Sea. Polar Res. 30, 15787 (2011). Observational study that identified warm Arctic/cold continental pattern associated with sea ice loss.

11. Cohen, J., Jones, J., Furtado, J. C. \& Tziperman, E. Warm Arctic, cold continents: a common pattern related to Arctic sea ice melt, snow advance, and extreme winter weather. Oceanography 26, 150-160 (2013).

12. Kug, J.-S. et al. Two distinct influences of Arctic warming on cold winters over North America and East Asia. Nat. Geosci. 8, 759-762 (2015). Showed clear link between warm temperatures in the Chukchi-East Siberian Seas and cold temperatures in North America east of the Rockies. Also supported previously shown link between warm temperatures in the Barents-Kara Seas and cold Siberia.

13. Sun, L., Perlwitz, J. \& Hoerling, M. What caused the recent 'Warm Arctic, Cold Continents' trend pattern in winter temperatures? Geophys. Res. Lett. 43, 5345-5352 (2016).

14. Cohen, J. \& Barlow, M. The NAO, the AO, and global warming: how closely related? J. Clim. 18, 4498-4513 (2005).

15. Cohen, J., Barlow, M. \& Saito, K. Decadal fluctuations in planetary wave forcing modulate global warming in late boreal winter. J. Clim. 22, 4418-4426 (2009).

16. Wegmann, M., Orsolini, Y. J. \& Zolina, O. Warm Arctic-cold Siberia: comparing the recent and the early 20th century Arctic warmings. Environ. Res. Lett. 13, https://doi.org/10.1088/1748-9326/aaa0b7 (2018).

17. Cohen, J., Furtado, J., Barlow, M., Alexeev, V. \& Cherry, J. Arctic warming, increasing fall snow cover and widespread boreal winter cooling. Environ. Res. Lett. 7, 014007 (2012).

Argued that Arctic amplification including melting sea ice and extensive snow cover was contributing to a negative Arctic Oscillation and cold continental temperature trends. Also demonstrated that model projected and observed winter temperature trends were diverging.

18. Coumou, D., Di Capua, G., Vavrus, S., Wang, L. \& Wang, S. The influence of Arctic amplification on mid-latitude summer circulation. Nat. Commun. 9, 2959 (2018).

19. Alexeev, V. A. et al. Vertical structure of recent Arctic warming from observed data and reanalysis products. Climatic Change 111, 215-239 (2012)

20. Vihma, T. in Climate Extremes: Patterns and Mechanisms (eds Wang, S.-Y. S. et al.) Ch. 2 (AGU Geophysical Monograph Series 226, 2017).

21. Boe, J., Hall, A. \& Qu, X. Current GCMs' unrealistic negative feedback in the Arctic. J. Clim. 22, 4682-4695 (2009).

22. Alexeev, V. A., Langen, P. L. \& Bates, J. R. Polar amplification of surface warming on an aquaplanet in 'ghost forcing' experiments without sea ice feedbacks. Clim. Dyn. 24, 655-666 (2005).

23. Manabe, S. \& Wetherald, R. T. The effects of doubling the $\mathrm{CO}_{2}$ concentration on the climate of a general circulation model. J. Atmos. Sci. 32, 3-15 (1975). An early paper that showed Arctic or polar amplification due to local feedbacks in model projections forced by anthropogenic greenhouse warming.

24. Stuecker, M. F. et al. Polar amplification dominated by local forcing and feedbacks. Nat. Clim. Change 8, 1076-1081 (2018).

25. Dai, A., Luo, D., Song, M. \& Liu, J. Arctic amplification is caused by sea-ice loss under increasing $\mathrm{CO}_{2}$. Nat. Commun. 10, 121 (2019).

26. Rigor, I. G., Wallace, M. \& Colony, R. Response of sea ice to the Arctic Oscillation. J. Clim. 15, 2648-2663 (2002). 
27. Zhang, X., Ikeda, M. \& Walsh, J. E. Arctic sea-ice and freshwater changes driven by the atmospheric leading mode in a coupled sea ice-ocean model. J. Clim. 16, 2159-2177 (2003).

28. Zhang, X., Sorteberg, A., Zhang, J., Gerdes, R. \& Comiso, J. C. Recent radical shifts in atmospheric circulations and rapid changes in Arctic climate system. Geophys. Res. Lett. 35, L22701 (2008).

Identified radical spatial changes in the large-scale atmospheric circulation showing a contracted/weakened Icelandic low and a northwestward extended/strengthened Siberian high; linked the amplified Arctic warming/accelerated decrease in sea ice in the Barents-Kara seas to Eurasian cooling.

29. Zhang, X. et al. Enhanced poleward moisture transport and amplified northern high-latitude wetting trend. Nat. Clim. Change 3, 47-51 (2013).

30. Park, D.-S., Lee, S. \& Feldstein, S. B. Attribution of the recent winter sea-ice decline over the Atlantic sector of the Arctic Ocean. J. Clim. 28, 4027-4033 (2015).

31. Gong, T., Feldstein, S. B. \& Lee, S. The role of downward infrared radiation in the recent Arctic winter warming trend. J. Clim. 30, 4937-4949 (2017).

32. Laliberte, F. \& Kushner, P. J. Midlatitude moisture contribution to recent Arctic tropospheric summertime variability. J. Clim. 27, 5693-5706 (2014).

33. Ding, Q. et al. Influence of high-latitude atmospheric circulation changes on summertime Arctic sea ice. Nat. Clim. Change 7, 289-295 (2017).

34. Perovich, D. K., Richter-Menge, J. A., Jones, K. F. \& Light, B. Sunlight, water, and ice: extreme Arctic sea ice melt during the summer of 2007. Geophys. Res. Lett. 35, https://doi.org/10.1029/2008gl034007 (2008).

35. Pistone, K., Eisenman, I. \& Ramanathan, V. Observational determination of albedo decrease caused by vanishing Arctic sea ice. Proc. Natl Acad. Sci. USA 111, 3322-3326 (2014).

36. Jeong, J.-H. et al. Intensified Arctic warming under greenhouse warming by vegetation-atmosphere-sea ice interaction. Environ. Res. Lett. 9, 094007 (2014)

37. Overland, J. E., Francis, J. A., Hanna, E. \& Wang, M. The recent shift in early summer Arctic atmospheric circulation. Geophys. Res. Lett. 39 L19804 (2012).

38. Serreze, M. C. \& Francis, J. A. The arctic amplification debate. Climatic Change 76, 241-264 (2006).

39. Screen, J. A. \& Simmonds, I. The central role of diminishing sea ice in recent Arctic temperature amplification. Nature 464, 1334-1337 (2010).

40. Pithan, F. et al. Role of air-mass transformations in exchange between the Arctic and mid-latitudes. Nat. Geosci. 11, 805-812 (2018).

41. Boisvert, L. N., Wu, D. L. \& Shie, C.-L. Increasing evaporation amounts seen in the Arctic between 2003 and 2013 from AIRS data. J. Geophys. Res. 120, 6865-6881 (2015)

42. Boisvert, L. N. \& Stroeve, J. C. The Arctic is becoming warmer and wetter as revealed by the Atmospheric Infrared Sounder. Geophys. Res. Lett. 42, 4439-4446 (2015).

43. Taylor, P. C., Hegyi, B. M., Boeke, R. C. \& Boisvert, L. N. On the increasing importance of air-sea exchanges in a thawing Arctic: a review. Atmos. 9, https://doi.org/10.3390/atmos9020041 (2018).

44. Winton, M. Amplified Arctic climate change: what does surface albedo feedback have to do with it? Geophys. Res. Lett. 33, L03701 (2006).

45. Wendisch, M. et al. The Arctic cloud puzzle: using ACLOUD/PASCAL multi-platform observations to unravel the role of clouds and aerosol particles in Arctic amplification. Bull. Am. Meteorol. Soc. 100, 841-871 (2019).

46. Kay, J. E. \& L'Ecuyer, T. Observational constraints on Arctic ocean clouds and radiative fluxes during the early 21 st century. J. Geophys. Res. Atmos. 118, 7219-7236 (2013).

47. Boeke, R. C. \& Taylor, P. C. Seasonal energy exchanges in sea ice retreat regions contribute to the inter-model spread in projected Arctic warming. Nat. Commun. 9, 5017 (2018).

48. Intrieri, J. M. et al. An annual cycle of Arctic surface cloud forcing at SHEBA. J. Geophys. Res. 107, https://doi.org/10.1029/2000JC000423 (2002).

49. Uttal, T. et al. Surface heat budget of the Arctic Ocean. Bull. Am. Meteorol. Soc. 83, 255-275 (2002).

50. Francis, J. A., Hunter, E., Key, J. R. \& Wang, X. Clues to variability in Arctic minimum sea ice extent. Geophys. Res. Lett. 32, https://doi.org/ 10.1029/2005GL024376 (2005)

51. Screen, J. A. Simulated atmospheric response to regional and Pan-Arctic sea-ice loss. J. Clim. 30, https://doi.org/10.1175/JCLI-D-16-0197.1 (2017). Observational and modelling showing the atmospheric to regional and pan-Arctic response to Arctic warming/sea ice loss.

52. Liu, Y. \& Key, J. R. Less winter cloud aids summer 2013 Arctic sea ice return from 2012 minimum. Environ. Res. Lett. 9, https://doi.org/ 10.1088/1748-9326/9/4/044002 (2014).

53. Lee, S. A theory for polar amplification from a general circulation perspective. Asia-Pac. J. Atmos. Sci. 50, 31-43 (2014).

54. Park, H.-S., Lee, S., Kosaka, Y., Son, S.-W. \& Kim, S.-W. The impact of Arctic winter infrared radiation on early summer sea ice. J. Clim. 28, 6281-6296 (2015).
55. Hegyi, B. M. \& Taylor, P. C. The regional influence of the Arctic Oscillation and Arctic Dipole on the wintertime Arctic surface radiation budget and sea ice growth. Geophys. Res. Lett. 44, 4341-4350 (2017).

56. Woods, C. \& Caballero, R. The role of moist intrusions in winter Arctic warming and sea ice decline. J. Clim. 29, 4473-4485 (2016).

57. Kim, B.-M. et al. Major cause of unprecedented Arctic warming in January 2016: Critical role of an Atlantic windstorm. Sci. Rep. 7, 40051 (2017).

58. Hegyi, B. M. \& Taylor, P. C. The unprecedented 2016-17 Arctic sea ice growth season: the crucial role of atmospheric rivers and longwave fluxes. Geophys. Res. Lett. 45, 5204-5212 (2018).

59. Messori, G., Woods, C. \& Caballero, R. On the drivers of wintertime temperature extremes in the High Arctic. J. Clim. 31, 1597-1618 (2018).

60. Holton, J. R. An Introduction to Dynamic Meteorology 2nd edn (Academic, 1979).

61. Barnes, E. A. Revisiting the evidence linking Arctic amplification to extreme weather in midlatitudes. Geophys. Res. Lett. 40, 4734-4739 (2013). Early paper that was sceptical of reported Arctic-mid-latitude linkages and found no evidence that Arctic amplification was contributing to increased blocking or extreme weather.

62. Screen, J. A. \& Simmonds, I. Exploring links between Arctic amplification and mid-latitude weather. Geophys. Res. Lett. 40, 959-964 (2013).

63. Rex, D. F. Blocking action in the middle troposphere and its effect upon regional climate. I. An aerological study of blocking action. Tellus $\mathbf{2}$, 196-211 (1950).

64. Rex, D. P. Blocking action in the middle troposphere and its effect upon regional climate. II. The climatology of blocking actions. Tellus 2, 275-301 (1950).

65. Quiroz, R. S. Tropospheric-stratospheric interaction in the major warming event of January-February 1979. Geophys. Res. Lett. 6, 645-648 (1979).

66. Quiroz, R. S. The association of stratospheric warmings with tropospheric blocking. J. Geophys. Res. 91, 5277-5285 (1986).

67. Martius, O., Polvani, L. M. \& Davies, H. C. Blocking precursors to stratospheric sudden warming events. Geophys. Res. Lett. 36, L14806 (2009).

68. Baldwin, M. P. \& Dunkerton, T. J. Stratospheric harbingers of anomalous weather regimes. Science 294, 581-584 (2001).

69. Kim, B.-M. et al. Weakening of the stratospheric polar vortex by Arctic sea-ice loss. Nat. Commun. 5, https://doi.org/10.1038/ncomms5646 (2014). Early paper that established stratospheric pathway for atmospheric response to sea ice loss in the Barents-Kara sea in both observations and modelling experiments.

70. Kretschmer, M. et al. More frequent weak stratospheric polar vortex states linked to mid-latitude cold extremes. Bull. Am. Meteorol. Soc. 99 49-60 (2018).

71. Honda, M., Inoue, J. \& Yamane, S. Influence of low Arctic sea-ice minima on anomalously cold Eurasian winters. Geophys. Res. Lett. 36, https://doi.org/10.1029/2008GL037079 (2009).

Early paper showing through model experiments that sea ice loss in the Barents-Kara Seas can force in cold Siberian temperatures by exciting a Rossby wave train.

72. Sillmann, J., Croci-Maspoli, M., Kallache, M. \& Katz, R. W. Extreme cold winter temperatures in Europe under the influence of North Atlantic atmospheric blocking. J. Clim. 24, 5899-5913 (2011).

73. Zhang, X., Lu, C. \& Guan, Z. Weakened cyclones, intensified anticyclones, and the recent extreme cold winter weather events in Eurasia. Environ. Res. Lett. 7, 044044 (2012).

74. Cohen, J., Pfeiffer, K. \& Francis, J. Warm Arctic episodes linked with increased frequency of extreme winter weather in the United States. Nat. Commun. 9, 869 (2018).

75. Johnson, N. C., Xie, S.-P., Kosaka, Y. \& Li, X. Increasing occurrence of cold and warm extremes during the recent global warming slowdown. Nat. Commun. 9, 1724 (2018).

76. Hanna, E. et al. Greenland Blocking Index daily series 1851-2015: analysis of changes in extremes and links with North Atlantic and UK climate variability and change. Int. J. Climatol. 38, 3546-3564 (2018).

77. Lee, S. H., Charlton-Perez, A. J., Furtado, J. C. \& Woolnough, S. J. Abrupt stratospheric vortex weakening associated with North Atlantic anticyclonic wave breaking. J. Geophys. Res. 124, https://doi.org/10.1029/2019JD030940 (2019).

78. Overland, J. E. et al. Nonlinear response of mid-latitude weather to the changing Arctic. Nat. Clim. Change 6, 992-999 (2016).

79. Shepherd, T. G. Effects of Arctic warming. Science 353, 989-990 (2016).

80. Overland, J. E. \& Wang, M. Resolving future Arctic/Midlatitude weather connections. Earth's Future 6, 1146-1152 (2018).

81. Screen, J. A. \& Francis, J. A. Contribution of sea-ice loss to Arctic amplification is regulated by Pacific Ocean decadal variability. Nat. Clim. Change 6, 856-860 (2016).

82. Osborn, T. J., Jones, P. D. \& Joshi, M. Recent United Kingdom and global temperature variations. Weather 72, 323-329 (2017). 
83. Li, F., Orsolini, Y. J., Wang, H., Gao, Y. \& He, S. Atlantic multidecadal oscillation modulates the impacts of Arctic sea ice decline. Geophys. Res. Lett. 45, 2497-2506 (2018).

84. Jaiser, R., Dethloff, K., Handorf, D., Rinke, A. \& Cohen, J. Impact of sea ice cover changes on the Northern Hemisphere atmospheric winter circulation. Tellus A 64, https://doi.org/10.3402/tellusa.v64i0.11595 (2012).

85. Semmler, T. et al. Seasonal atmospheric responses to reduced Arctic sea ice in an ensemble of coupled model simulations. J. Clim. 29, 5893-5913 (2016).

86. Basu, S., Zhang, X. \& Wang, Z. Eurasian winter storm activity at the end of the century: a CMIP5 multi-model ensemble projection. Earth's Future 6, 61-70 (2018).

87. Smith, K., Kushner, P. J. \& Cohen, J. The role of linear interference in Northern Annular Mode variability associated with Eurasian snow cover extent. J. Clim. 24, 6185-6202 (2011).

88. Wu, Y. \& Smith, K. L. Response of Northern Hemisphere midlatitude circulation to Arctic amplification in a simple atmospheric general circulation model. J. Clim. 29, 2041-2058 (2016).

89. Cohen, J., Barlow, M., Kushner, P. J. \& Saito, K. Stratosphere-troposphere coupling and links with Eurasian land surface variability. J. Clim. 20, 5335-5343 (2007).

90. Butler, A. H., Sjoberg, J. P., Seidel, D. J. \& Rosenlof, K. H. A sudden stratospheric warming compendium. Earth Syst. Sci. Data 9, 63-76 (2017).

91. Newson, R. L. Response of a general circulation model of the atmosphere to removal of the Arctic ice-cap. Nature 241, 39-40 (1973).

92. Warshaw, M. \& Rapp, R. R. An experiment on the sensitivity of a global circulation model. J. Appl. Meteorol. 12, 43-49 (1973).

93. Magnusdottir, G., Deser, C. \& Saravanan, R. The effects of North Atlantic SST and sea-ice anomalies on the winter circulation in CCM3. Part I: Main features and storm track characteristics of the response. J. Clim. 17, 857-876 (2004).

94. Deser, C., Magnusdottir, G., Saravanan, R. \& Phillips, A. The effects of North Atlantic SST and sea-ice anomalies on the winter circulation in CCM3. Part II: Direct and indirect components of the response. J. Clim. 17, 877-889 (2004).

95. Alexander, M. A. et al. The atmospheric response to realistic Arctic sea-ice anomalies in an AGCM during winter. J. Clim. 17, 890-905 (2004).

96. Singarayer, J. S., Valdes, P. J. \& Bamber, J. L. The atmospheric impact of uncertainties in recent Arctic sea-ice reconstructions. J. Clim. 18, 3996-4012 (2005).

Modelling paper that showed no relationship between sea ice variability and the North Atlantic Oscillation, an early precursor for many more modelling studies.

97. McCusker, K. E., Fyfe, J. C. \& Sigmond, M. Twenty-five winters of unexpected Eurasian cooling unlikely due to Arctic sea ice loss. Nat. Geosci. 9, 838-842 (2016).

98. Blackport, R. \& Kushner, P. J. Isolating the atmospheric circulation response to Arctic sea ice loss in the coupled climate system. J. Clim. 30, 2163-2185 (2017).

99. Ogawa, F. et al. Evaluating impacts of recent Arctic sea ice loss on the Northern Hemisphere winter climate change. Geophys. Res. Lett. 45, 3255-3263 (2018).

100. Sun, L., Deser, C. \& Tomas, R. A. Mechanisms of stratospheric and tropospheric circulation response to projected Arctic sea ice loss. J. Clim. 28, 7824-7845 (2015).

101. McKenna, C. M., Bracegirdle, T. J., Shuckburgh, E. F., Haynes, P. H. \& Joshi, M. M. Arctic sea-ice loss in different regions leads to contrasting Northern Hemisphere impacts. Geophys. Res. Lett. 44, https://doi.org/ 10.1002/2017GL076433 (2017).

102. Nishii, K., Nakamura, H. \& Orsolini, Y. J. Geographical dependence observed in blocking high influence on the stratospheric variability through enhancement and suppression of upward planetary-wave propagation. J. Clim. 24, 6408-6423 (2011).

103. Petoukhov, V. \& Semenov, V. A link between reduced Barents-Kara sea ice and cold winter extremes over northern continents. J. Geophys. Res. 115, https://doi.org/10.1029/2009JD013568 (2010).

104. Chen, H. W., Alley, R. B. \& Zhang, F. Interannual Arctic sea ice variability and associated winter weather patterns: a regional perspective for 1979-2014. J. Geophys. Res. Atmos. 121, https://doi.org/10.1002/2016JD024769 (2016).

105. Mori, M., Watanabe, M., Shiogama, H., Inoue, J. \& Kimoto, M. Robust Arctic sea-ice influence on the frequent Eurasian cold winters in past decades. Nat. Geosci. 7, 869-873 (2014)

Model study demonstrating that sea ice loss in the Barents-Kara Seas forces increased blocking and cold temperatures across Eurasia in winter.

106. Mori, M., Kosaka, Y., Watanabe, M., Nakamura, H. \& Kimoto, M. A reconciled estimate of the influence of Arctic sea-ice loss on recent Eurasian cooling. Nat. Clim. Change 9, 123-129 (2019).

107. Luo, D., Xiao, Y., Yao, Y., Dai, A., Simmonds, I. \& Franzke, C. Impact of Ural blocking on winter warm Arctic-cold Eurasian anomalies. Part I: Blocking-induced amplification. J. Clim. 29, 3925-3947 (2016).
108. Chen, X. \& Luo, D. Arctic sea ice decline and continental cold anomalies: upstream and downstream effects of Greenland blocking. Geophys. Res. Lett. 44, 3411-3419 (2017).

109. Vihma, T. et al. Effects of the tropospheric large-scale circulation on European winter temperatures during the period of amplified Arctic warming. Int. J. Climatol., https://doi.org/10.1002/joc.6225 (2019).

110. Overland, J. E. \& Wang, M. Large-scale atmospheric circulation changes are associated with the recent loss of Arctic sea ice. Tellus 62A, 1-9 (2010).

111. Outten, S. D. \& Esau, I. A link between Arctic sea ice and recent cooling trends over Eurasia. Climatic Change 110, 1069-1075 (2012).

112. Zhang, P. et al. A stratospheric pathway linking a colder Siberia to Barents-Kara sea ice loss. Sci. Adv. 4, eaat6025 (2018).

113. Screen, J. A. et al. Consistency and discrepancy in the atmospheric response to Arctic sea-ice loss across climate models. Nat. Geosci. 11, 155-163 (2018).

114. Francis J. \& Vavrus, S. Evidence for a wavier jet stream in response to rapid Arctic warming. Environ. Res. Lett. 10, https://doi.org/10.1088/1748-9326/ 10/1/014005 (2015).

115. Di Capua, G. \& Coumou, D. Changes in meandering of the Northern Hemisphere circulation. Environ. Res. Lett. 11, https://doi.org/10.1088/ 1748-9326/11/9/094028 (2016).

116. Hoshi, K. et al. Weak stratospheric polar vortex events modulated by the Arctic sea ice loss. J. Geophys. Res. 124, https://doi. org/10.1029/2018JD029222 (2019).

117. Yao, Y., Luo, D., Dai, A. \& Simmonds, I. Increased quasi stationarity and persistence of Ural blocking and Eurasian extreme cold events in response to Arctic warming. Part I: Insights from observational analyses. J. Clim. 30, 3549-3568 (2017).

118. Nakamura, T. et al. A negative phase shift of the winter AO/NAO due to the recent Arctic sea-ice reduction in late autumn. J. Geophys. Res. 120, 3209-3227 (2015)

119. Jaiser, R. et al. Atmospheric winter response to Arctic sea ice changes in reanalysis data and model simulations. J. Geophys. Res. 121, 7564-7577 (2016)

120. Orsolini, Y., Senan, R., Benestad, R. E. \& Melsom, A. Autumn atmospheric response to the 2007 low Arctic sea ice extent in coupled oceanatmosphere hindcasts. Clim. Dyn. 38, 2437-2448 (2012).

121. Romanowsky, E. et al. The role of stratospheric ozone for Arctic-midlatitude linkages, Sci. Rep. https://doi.org/10.1038/s41598-019-43823-1 (2019).

122. Deser, C., Tomas, R. A. \& Sun, L. The role of ocean-atmosphere coupling in the zonal-mean atmospheric response to Arctic sea ice loss. J. Clim. 28, 2168-2186 (2015).

123. Screen, J. A., Deser, C., Simmonds, I. \& Tomas, R. Atmospheric impacts of Arctic sea-ice loss, 1979-2009: separating forced change from atmospheric internal variability. Clim. Dyn. 43, 333-344 (2014).

124. Smith, D. M. et al. Atmospheric response to Arctic and Antarctic sea ice: the importance of ocean-atmosphere coupling and the background state. J. Clim. 30, 4547-4565 (2017).

125. Ayarzagüena, B. \& Screen, J. A. Future Arctic sea-ice loss reduces severity of cold air outbreaks in midlatitudes. Geophys. Res. Lett. 43, 2801-2809 (2016).

126. Chen, H. W., Zhang, F. \& Alley, R. B. The robustness of midlatitude weather pattern changes due to Arctic sea ice loss. J. Clim. 29, 7831-7849 (2016).

127. Charlton-Perez, A. et al. On the lack of stratospheric dynamical variability in low-top versions of the CMIP5 models. J. Geophys. Res. 118, 2494-2505 (2013)

128. Kirtman, B. P. et al. The North American Multimodel Ensemble. Bull. Am. Meteorol. Soc. 17, 585-601 (2014).

129. Wallace, J. M., Held, I. M., Thompson, D. W. J., Trenberth, K. E. \& Walsh, J. E. Global warming and winter weather. Science 343, 729-730 (2014).

130. Kintisch, E. Into the maelstrom. Science 344, 250-253 (2014).

131. Gramling, C. Arctic impact. Science 347, 818-821 (2015).

132. Francis, J. A, Vavrus, S. J. \& Cohen, J. Amplified Arctic warming and mid-latitude weather: new perspectives on emerging connections. WIREs Clim. Change E474, https://doi.org/10.1002/wcc.474 (2017).

133. Vavrus, S. J. The influence of Arctic amplification on midlatitude weather and climate. Curr. Clim. Change Rep. 4, 238-249 (2018).

134. Smith, D. M. et al. The Polar Amplification Model Intercomparison Project (PAMIP) contribution to CMIP6: investigating the causes and consequences of polar amplification. Geosci. Model Dev. 12, 1139-1164 (2019).

135. Wilks, D. Statistical Methods in the Atmospheric Sciences (Academic, 2006).

136. Screen, J. A. The missing Northern European cooling response to Arctic sea ice loss. Nat. Commun. 8, 14603 (2017).

137. Ding, Q. et al. Tropical forcing of the recent rapid Arctic warming in northeastern Canada and Greenland. Nature 509, 209-212 (2014).

138. Schwartz, C. \& Garfinkel, C. I. Relative roles of the MJO and stratospheric variability in North Atlantic and European winter climate. J. Geophys. Res. 44, https://doi.org/10.1002/2016JD025829 (2017).

Publisher's note Springer Nature remains neutral with regard to jurisdictional claims in published maps and institutional affiliations.

(c) Springer Nature Limited 2019 


\section{Methods}

In Fig. 1, air temperature (variable 'ta') was retrieved from the Earth System Grid Federation (ESGF) archive for the reanalysis of the Collaborative REAnalysis Technical Environment (CREATE-MERRA-2, ERA5, JRA-55 and CFSR) for the period December 1980 to February 2019 and was averaged on pressure level to obtain a seasonal and zonal mean. A linear trend was then computed at each point in the latitude-pressure plane. The trend was assumed to be distributed according to a $t$-distribution. For the RCP 8.5 scenario of the CMIP5 project, trends were combined by first taking an average over all simulations for each model, then averaging over all models over an institute and then averaging over institutes to obtain a multimodel mean. The distribution of trends at each point in the latitude-pressure plane and for each season was found through bootstrapping with 50,000 samples. For each sample, we randomly select one simulation for each model, combine all the chosen simulations to obtain a multimodel mean, and then compute a trend using this multimodel mean time series. By repeating this procedure, we obtain a distribution of trends. From this distribution of trends for each season, we can find at each point in the latitude-pressure plane the $P$-value for the null hypothesis of no trend. We then apply the false discovery rate correction ${ }^{135}$ with a global $P$-value of 0.05 . The false discovery rate correction is a field significance test that calculates a new threshold $P$-value based on the distribution of $P$-values.

For the reanalyses of the Collaborative REAnalysis Technical EnvironmentIntercomparison Project, we applied the exact same analysis except that the 50,000 bootstrap samples for the trend distribution were generated in a slightly different fashion. Instead of selecting one simulation for each reanalysis (there is only one), we selected a random trend from the $t$-distribution of trends for each of the reanalyses. The linear air-temperature trend in Fig. 1c, d is based on the 16-member Atmosphere Model Intercomparison (AMIP) simulations with the 'higher-top' version of the NCAR's Community Atmosphere Model version 5 (CAM5 ${ }^{139}$ ) for 1980/1981 to 2015/2016. In Fig. 1c, the air temperature is first averaged zonally and seasonally and over all 16 members before the linear trend is calculated. For Fig. 1d we chose the ensemble member whose trend best matches the observation. Significance was assessed in the same way as for the other panels. With a single simulation, the method reduces to a one-sided $t$-test onto which we apply the false discovery rate.

In Fig. 3, spatial relations among regional and full Arctic 850-hPa air temperature and $\mathrm{NH}$ near-surface temperatures composited were examined with a series of composites computed with ERA-Interim Reanalysis ${ }^{140}$. Areaaveraged reference means were formed from 1981 to 2010 in both the near-surface temperature and $850-\mathrm{hPa}$ air temperature for the Barents-Kara Sea $\left(65^{\circ} \mathrm{N}\right.$ to $80^{\circ}$ $\mathrm{N}, 10^{\circ} \mathrm{E}$ to $\left.100^{\circ} \mathrm{E}\right)$, Canadian Archipelagos and Baffin Bay $\left(60^{\circ} \mathrm{N}\right.$ to $90^{\circ} \mathrm{N}, 80^{\circ} \mathrm{W}$ to $50^{\circ} \mathrm{W}$ ), east of Greenland $\left(65^{\circ} \mathrm{N}\right.$ to $80^{\circ} \mathrm{N}, 40^{\circ} \mathrm{W}$ to $\left.10^{\circ} \mathrm{W}\right)$, and the Chukchi and Bering Seas $\left(65^{\circ} \mathrm{N}\right.$ to $80^{\circ} \mathrm{N}, 170^{\circ} \mathrm{E}$ to $\left.210^{\circ} \mathrm{E}\right)$. The near-surface temperature anomalies were regressed onto 850 -hPa air temperature using daily data in winter (DJF) $1979 / 80$ to $2018 / 19$; all data are linearly detrended when the 850 -hPa air temperatures are between 0.5 and 3 standard deviations above the climatological average. Completing this analysis is the polar cap temperature at $850 \mathrm{hPa}$, areaaveraged from $65^{\circ} \mathrm{N}$ to $90^{\circ} \mathrm{N}$ and similarly regressed with $\mathrm{NH}$ near-surface temperatures (Fig. 3e). A comparable analysis was completed with HadGEM2 data The model data are from 1,600 winters simulated under present-day conditions using the HadGEM2-ES model. Specifically, we ran 400 realizations of 5 years in length from 2008 to 2012 under the RCP8.5 scenario. Runs were started on 1 January, so there are only four full winters in each 5-year run. Initial conditions for the 400 realizations were generated by first branching off 16 different realizations at the year 1990 from historical simulations and then forcing with historical/ RCP8.5 forcing until 2008. At year 2008, 25 realizations were branched off each of the 16 different climate states by using the atmospheric initial conditions from 25 different dates (from 1 January to 25 January). Forced response to sea ice in Fig. $3 \mathrm{k}-\mathrm{o}$ is from ref. ${ }^{51}$.

In Fig. 4, the linear trend for December, January, February and March (DJFM) 2-m temperature was computed using both the National Centers for Environmental Prediction (NCEP) Reanalysis ${ }^{141}$ and the November forecast components of the North American Multi-Model Ensemble (NMME ${ }^{128}$ ). Included in the NMME were models from the Canadian Meteorological Center (CMC1-CanCM3 and CMC2-CanCM4), the Center for Ocean-Land-Air Studies (COLA-RSMAS-CCSM4) and the Geophysical Fluid Dynamics Laboratory (GFDL-CM2p5-FLOR-A06 and GFDL-CM2p5-FLOR-B01). Reference means were computed from 1981 to 2010 for NCEP and 1982 to 2010 for NMME components (NMME hindcasts begin in 1982). For the NMME components, the zero-hour forecasts were treated as analyses for the DJFM period, with each model treated individually; so, for example, the CMC1-CanCM3 analyses for 1982-2010 were used to form the reference mean for computing anomalies in the CMC1CanCM3 November forecasts for DJFM. For the midlatitude $\mathrm{NH}\left(30^{\circ} \mathrm{N}\right.$ to $60^{\circ}$ N), all annual anomalies from 1989 to 2017 were computed for observed (NCEP) and forecast (NMME November for DJFM), using all ensemble members of the individual NMME components (Fig. 4a with all in grey, Fig. $4 \mathrm{~b}$ with NCEP in blue and NMME in red). The annual mean of all NMME components and ensembles was then used to compute the linear trend from 1989 to 2017 (Fig. 4c in red) for comparison to the NCEP linear trend (Fig. $4 \mathrm{c}$ in blue). For broader comparison, these calculations were repeated for the entire $\mathrm{NH}$ and Arctic only with trend lines for NMME (green/red) and NCEP (black/blue) shown in Fig. 4d. Anomalies are calculated relative to climatology from reanalysis for 1981-2010 and from NMME 1982-2010 winter mean respectively.

In Supplementary Fig. 1a, the near-surface mean temperatures zonally averaged from $90^{\circ} \mathrm{S}$ to $90^{\circ} \mathrm{N}$ and from 1960 to 2018 are plotted. Data are from NASA/GISS ${ }^{142}$. In Supplementary Fig. 1b, 2-m air-temperature anomalies and the 5 -year running mean for December through February are plotted for the Arctic, midlatitude land areas and the difference between the Arctic and midlatitude land areas. Climatology used is the 30-year average of 1981-2010. Data are from NCEP/ NCAR reanalysis data ${ }^{141}$

In Supplementary Fig. $2 \mathrm{a}$ and $\mathrm{b}$, the linear trend is computed for each grid cell in the Hadley Centre-Climate Research Unit global temperature dataset- 4 (HadCRUT4 ${ }^{143}$ ) for land surface only, multiplied by 10 to provide a trend in ${ }^{\circ} \mathrm{C}$ per decade for the months October through December, and January through March, respectively, from 1988 to 2008. In Supplementary Fig. 2c, d, the average surface temperature anomaly is computed for each grid cell in the Hadley Centre CRU land surface data for the months October through December, and January through March, respectively, from 2008 to 2018. Climatology used is the 30-year average of 1981-2010.

The simulations presented in Supplementary Figs. 5 and 6 are conducted at NOAA's Earth System Research Laboratory Physical Science Division. These are AMIP simulations from 1979 to present day, forced by observed GHGs, ozone, aerosols and surface lower boundaries (that is, sea surface temperature and sea ice conditions). Three model simulations from NCAR 'low-top' Community Atmosphere Model Version 5 (30 members $\left.{ }^{144}\right)$, NCAR 'higher-top' CAM5 (16 members $\left.{ }^{139}\right)$ and ECHAM5 (30 members $\left.{ }^{145}\right)$ are used for the decadal temperature trend across 1980-2015.

In Supplementary Fig. 5, the air temperature is first averaged zonally and seasonally and over all available members before the linear trend is assessed.

In Supplementary Fig. 7, we tabulated the number of disruptive northeast snowstorms by decade from the NOAA website.

In Supplementary Fig. 8, the linear trend in sea ice concentration from the Hadley Centre Sea Ice and Sea Surface Temperature data set (HadISST ${ }^{146}$ ) is shaded.

In Supplementary Fig. 9, the winter near-surface air-temperature anomalies and the linear trend for DJFM were computed using both the NCEP Reanalysis and the November forecast components of the NMME models for the tropics $\left(0^{\circ}-30^{\circ} \mathrm{N}\right)$ and midlatitude oceans $\left(30^{\circ}-60^{\circ} \mathrm{N}\right)$. Climatology used for reanalysis is 1981-2010 and that for NMME is 1982-2010 winter mean.

In Supplementary Fig. 10, reanalysis is repeated as in Fig. 4 and Supplementary Fig. 9, except that the climatology used is 1981-2010 winter mean from the NCEP Reanalysis for all NMME temperature anomalies.

Supplementary Fig. 11 is same as Fig. 4 but for summer (June, July and August: JJA).

In Supplementary Fig. 12, we computed the difference in the trends from 1989-2019 between winter (DJF) and summer (JJA). Shown on the left-hand side is the zonal mean difference in the trends.

\section{Data availability}

The air-temperature data in AMIP simulations and detailed forcing information for Fig. 1 are available at: https://go.nature.com/34c5lJT. Data and detailed model simulation information for Supplementary Fig. 5 can be found at: https://go.nature com/34c5lJT. Data for Supplementary Fig. 7 are from https://www.ncdc.noaa.gov/ snow-and-ice/rsi/nesis. All other data that support the findings of this study are available within the paper and its Supplementary Information files.

\section{References}

139. Richter, J., Deser, C. \& Sun, L. Effects of stratospheric variability on El Niño teleconnections. Environ. Res. Lett. 10, 124021 (2015).

140. Dee, D. P. et al. The ERA-Interim reanalysis: configuration and performance of the data assimilation system. Q. J. R. Meteorol. Soc. 137, 553-597 (2011)

141. Kalnay, E. et al. The NCEP/NCAR 40-year reanalysis project. Bull. Am. Meteorol. Soc. 77, 437-471 (1996).

142. Hansen, J., Ruedy, R., Sato, M. \& Lo, K. Global surface temperature change. Rev. Geophys. 48, RG4004 (2010).

143. Morice, C. P., Kennedy, J. J., Rayner, N. A. \& Jones, P. D. Quantifying uncertainties in global and regional temperature change using an ensemble of observational estimates: the HadCRUT4 dataset. J. Geophys. Res. 108117, D08101 (2012).

144. Neale, R. B. et al. Description of the NCAR Community Atmosphere Model (CAM 5.0). NCAR Technical Note NCAR/TN-486+STR (National Center of Atmospheric Research, 2012).

145. Roeckner, E. et al. The atmospheric general circulation model ECHAM5. Part I: Model description. Technical Report 349 (Max Planck Institute for Meteorology, 2003).

146. Rayner, N. A. et al. Global analyses of sea surface temperature, sea ice, and night marine air temperature since the late nineteenth century. J. Geophys. Res. 108, 4407 (2003) 


\section{Acknowledgements}

We thank R. Blackport, C. Deser, L. Sun, J. Screen and D. Smith for discussions and suggested revisions to the manuscript. We also thank J. Screen and L. Sun for model data. A. Amin helped to create Fig. 2. US CLIVAR logistically and financially supported the Arctic-Midlatitude Working Group and Arctic Change and its Influence on Mid-Latitude Climate and Weather workshop that resulted in this article. J.C. is supported by the US National Science Foundation grants AGS-1657748 and PLR-1504361, 1901352. M.W. acknowledges funding by the Deutsche Forschungsgemeinschaft project no. 268020496TRR 172, within the Transregional Collaborative Research Center "Arctic Amplification: Climate Relevant Atmospheric and Surface Processes, and Feedback Mechanisms (AC) ${ }^{3 \text { ". }}$ T.V. was supported by the Academy of Finland grant 317999. J.O. was supported by the NOAA Arctic Research Program. J.F. was supported by the Woods Hole Research Center. S.W. and H.G. are supported by the US DOE Award Number DE-SC0016605. J.Y. was supported by the Korea Meteorological Administration Research and Development Program under grant KMI2018-01015 and National Research Foundation grant NRF_2017R1A2B4007480. D.H. is supported by the Helmholtz Association of German Research Centers (grant FKZ HRSF-0036, project POLEX). The authors acknowledge the World Climate Research Programme's Working Group on Coupled Modelling, which is responsible for CMIP, and thank the climate modelling groups (listed in Supplementary Table 1) for producing and making available their model output. For CMIP, the US Department of Energy's PCMDI provides coordinating support and led development of software infrastructure in partnership with the Global Organization for Earth System Science Portals.

\section{Author contributions}

J.C. and X.Z. co-led the review and designed the synthesis research. J.C. took a lead in writing the article with input from X.Z., J.F., J.O., P.C.T., S.L., D.C., D.H., T.S., T.V., T.J. and all the other authors. F.L. created Fig. 1. P.C.T. and S.L. together with A. Amin created Fig. 2. J.C. and K.P. created Fig. 3. J. Cohen and K.P. created Fig. 4. J.C. created the figures for Box 1 and Box 2. J.F. assisted with manuscript revision.

\section{Competing interests}

The authors declare no competing interests.

\section{Additional information}

Supplementary information is available for this paper at https://doi.org/10.1038/ s41558-019-0662-y.

Correspondence should be addressed to J.C.

Peer review information Nature Climate Change thanks Scott Sheridan and the other, anonymous, reviewer(s) for their contribution to the peer review of this work.

Reprints and permissions information is available at www.nature.com/reprints. 
In the format provided by the authors and unedited.

\title{
Divergent consensuses on Arctic amplification influence on midlatitude severe winter weather
}

\author{
J. Cohen ${ }^{1,2 \star}$, X. Zhang ${ }^{3}{ }^{3}$, J. Francis ${ }^{4}$, T. Jung ${ }^{5,6}$, R. Kwok , J. Overland ${ }^{8}$, T. J. Ballinger ${ }^{9}{ }^{9}$, \\ U. S. Bhatt ${ }^{3}$, H. W. Chen ${ }^{10,11}$, D. Coumou ${ }^{12,13}$, S. Feldstein ${ }^{11}$, H. Gu' ${ }^{14}$, D. Handorf ${ }^{5}$, G. Henderson ${ }^{15}$, \\ M. Ionita ${ }^{5}$, M. Kretschmer ${ }^{13}$, F. Laliberte ${ }^{16}$, S. Lee ${ }^{11}$, H. W. Linderholm ${ }^{17}{ }^{1718}$, W. Maslowski ${ }^{19}$, Y. Peings ${ }^{20}$, \\ K. Pfeiffer ${ }^{1}$, I. Rigor ${ }^{21}$, T. Semmler ${ }^{5}{ }^{5}$, J. Stroeve ${ }^{22}$, P. C. Taylor ${ }^{23}$, S. Vavrus ${ }^{24}$, T. Vihma ${ }^{25}$, \\ S. Wang ${ }^{14}$, M. Wendisch ${ }^{26}$, Y. Wu ${ }^{27}$ and J. Yoon ${ }^{28}$
}

\footnotetext{
${ }^{1}$ Atmospheric and Environmental Research Inc., Lexington, MA, USA. ${ }^{2}$ Massachusetts Institute of Technology, Cambridge, MA, USA. ${ }^{3}$ University of Alaska

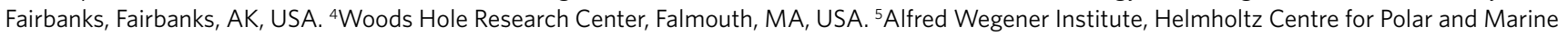
Research, Bremerhaven, Germany. ${ }^{6}$ University of Bremen, Bremen, Germany. ${ }^{7}$ Jet Propulsion Laboratory, Pasadena, CA, USA. ${ }^{8} \mathrm{NOAA}$ /PMEL, Seattle, WA, USA. ' Department of Geography, Texas State University, San Marcos, TX, USA. ${ }^{10}$ Lund University, Lund, Sweden. "Pennsylvania State University, State College, PA, USA. ${ }^{12}$ Potsdam Institute for Climate Impact Research, Potsdam, Germany. ${ }^{13}$ Vrije Universiteit Amsterdam, Amsterdam, the Netherlands. ${ }^{14}$ Utah Climate Center/Department of Plants, Soils and Climate, Utah State University, Logan, UT, USA. ${ }^{15}$ United States Naval Academy, Annapolis, MD, USA. ${ }^{16}$ Environment and Climate Change Canada, Gatineau, Quebec, Canada. ${ }^{17}$ University of Gothenburg, Gothenburg, Sweden. ${ }^{18}$ University of Cambridge, Cambridge, UK. ${ }^{19}$ Naval Postgraduate School, Monterey, CA, USA. ${ }^{20}$ University of California, Irvine, CA, USA. ${ }^{21}$ University of Washington, Seattle, WA, USA. ${ }^{22}$ University College London, London, UK. ${ }^{23}$ NASA Langley Research Center, Hampton, VA, USA. ${ }^{24}$ University of Wisconsin, Madison, WI, USA. ${ }^{25}$ Finnish Meteorological Institute, Helsinki, Finland. ${ }^{26}$ University of Leipzig, Leipzig, Germany. ${ }^{27}$ Lamont-Doherty Earth Observatory, Columbia University, Palisades, NY, USA. ${ }^{28}$ Gwangju Institute of Science and Technology, Gwangju, South Korea. ${ }^{\star}$ e-mail: jcohen@aer.com
} 


\section{Supplementary Information \\ Divergent consensuses on Arctic amplification influence on mid-}

\section{latitude severe winter weather}

J. Cohen ${ }^{1,2}$, X. Zhang 3 , J. Francis ${ }^{4}$, T. Jung 5,6, R. Kwok ${ }^{7}$, J. Overland ${ }^{8}$, T. J. Ballinger ${ }^{9}$, U. S. Bhatt ${ }^{3}$, H. W. Chen ${ }^{10}$, D. Coumou ${ }^{11,12}$, S. Feldstein ${ }^{13}$, H. Gu ${ }^{14}$, D. Handorf ${ }^{5}$, G. Henderson ${ }^{15}$, M. Ionita $^{5}$, M. Kretschmer ${ }^{12}$, F. Laliberte ${ }^{16}$, S. Lee ${ }^{13}$, H. W. Linderholm ${ }^{17,18}$, W. Maslowski ${ }^{19}$, Y. Peings $^{20}$, K. Pfeiffer ${ }^{1}$, I. Rigor ${ }^{21}$, T. Semmler ${ }^{5}$, J. Stroeve ${ }^{22}$, P. C. Taylor ${ }^{23}$, S. Vavrus ${ }^{24}$, T. Vihma ${ }^{25}$, S. Wang ${ }^{14}$, M. Wendisch ${ }^{26}$, Y. Wu ${ }^{27}$, J. Yoon ${ }^{28}$

\footnotetext{
${ }^{1}$ Atmospheric and Environmental Research, Inc. ${ }^{2}$ Massachusetts Institute of Technology. ${ }^{3}$ University of Alaska Fairbanks. ${ }^{4}$ Woods Hole Research Center. ${ }^{5}$ Alfred Wegener Institute Helmholtz Centre for Polar and Marine Research. ${ }^{6}$ University of Bremen. ${ }^{7}$ Jet Propulsion Laboratory.

${ }^{8}$ NOAA/PMEL. ${ }^{9}$ Department of Geography, Texas State University. ${ }^{10}$ Lund University. ${ }^{11}$ Potsdam Institute for Climate Impact Research. ${ }^{12} \mathrm{VU}$ Amsterdam. ${ }^{13}$ Pennsylvania State University. ${ }^{14}$ Utah Climate Center/Dept. PSC/Utah State Univ. ${ }^{15}$ United States Naval Academy. ${ }^{16}$ Environment and Climate Change Canada. ${ }^{17}$ University of Gothenburg. ${ }^{18}$ University of Cambridge. ${ }^{19}$ Naval Postgraduate School. ${ }^{20}$ University of California, Irvine. ${ }^{21}$ University of Washington. ${ }^{22}$ University College London. ${ }^{23}$ NASA Langley Research Center. ${ }^{24}$ University of Wisconsin, Madison.

${ }^{25}$ Finnish Meteorological Institute. ${ }^{26}$ University of Leipzig. ${ }^{27}$ Lamont-Doherty Earth Observatory, Columbia University. ${ }^{28}$ Gwangju Institute of Science and Technology.
}

\section{Pattern of Temperature Anomalies}

The Northern Hemisphere $(\mathrm{NH})$ winter temperature anomaly pattern during the era of Arctic amplification (AA) has previously been reported to resemble the pattern of variability associated with the negative phase of the Arctic Oscillation $(\mathrm{AO})^{1}$. Comparison of the winter temperature trends from 1989-2008 with the pattern of variability associated with the negative phase of the AO shows a similar or common pattern (Supplementary Figure 3a,c). However, the winter temperature anomalies from 2009-2019 do show a somewhat different pattern with relatively cold temperatures in the interior of the North American and Eurasian continents respectively and 
relatively mild temperatures elsewhere. This pattern resembles less the negative AO pattern of variability and possibly more the pattern of variability related to November Barents-Kara Sea ice extent anomalies (Supplementary Figure 3b,d). This change in the temperature pattern of variability may or not be a manifestation of the growing influence of sea ice decline on NH winter temperatures in the most recent decade. Also, even though the cooling in Eurasia has received most of the attention ${ }^{2}$, the cold anomalies on the North American continent over the past decade are of comparable magnitude to those in Eurasia.

\section{Model vs. Observational Studies}

In an effort to demonstrate the divide in the community and the divide between observational and modeling studies we have created a bar graph listing the number of observational/modeling studies supporting that AA is linked with an increase in severe winter weather and observational/modeling studies supporting that AA is not linked with an increase in severe winter weather (Supplementary Figure 4). We estimate that the number of observational and modeling studies are nearly equal, and of course some studies are both. The most lopsided difference is the number of observational studies that support a link between AA and severe winter weather and observational studies that do not. The number of modeling studies that support a link between AA and severe winter weather and modeling studies that do not are more equitably distributed, but we estimate that the number of modeling studies that do not support a link between AA and severe winter weather is greater. In addition, as we show throughout the article, the large ensembles of free-running models including CMIP5, AMIP and the NMME all support that there is no link between AA and increased severe winter weather across the mid-latitudes. 


\section{Arctic Amplification Mechanisms}

\section{Sea Ice}

Accelerated Arctic warming has led to, and partly resulted from, a dramatic decline in perennial sea ice cover ${ }^{3,4}$, which has intensified over the last few decades, resulting in a record minimum sea ice extent in September 2007 and a new record in 2012. Seasonally, sea ice decline is most prominent over the western Arctic Ocean in summer and over the Nordic/Barents/Kara Seas in winter. Additionally, the lengthening of the sea ice-free season has been shown to have influenced the interactions between the Arctic atmosphere and surface ${ }^{5}$ including increases in surface turbulent fluxes from the ocean to the atmosphere ${ }^{6}$.

Changes in Arctic sea ice during the satellite era have been argued to represent a fundamental change in the Arctic climate system representing a shift from a system dominated by thick, multiyear ice to a "new Arctic" dominated by thinner, first year ice ${ }^{3,4}$, These changes in sea ice cover, as with near-surface air temperature, exhibit a seasonal character marked by the largest changes in fall and winter seasons. However, sea ice decline is also evident throughout summer, unlike Arctic amplification (AA). The character of Arctic climate change provides clues as to the physical mechanisms driving AA including the role of natural variability ${ }^{7}$.

During winter, sea ice decouples the ocean surface from the overlying atmosphere, preventing moderation of Arctic air masses by latent and sensible heat fluxes from the Arctic Ocean. Furthermore, snow accumulations on sea ice mimic the cooling impacts of snow cover over land and hence amplify polar cooling during the long polar night. Given these seasonal roles for Arctic sea ice, even small changes in sea ice cover cause dramatic changes on Arctic climate. For example, anomalously low sea ice during the summer exposes darker (i.e., low albedo) ocean water 
to solar radiation, producing strong Arctic warming via absorption of solar radiation in the uppermost ocean layer, and anomalous latent and sensible heat fluxes. This reduction in summer sea ice extent subsequently can affect winter re-growth of Arctic sea ice, allowing for warmer and moister Arctic air masses, particularly over nearby continents. The ensuing feedback leads to amplified warming of the Arctic relative to the rest of the globe ${ }^{8,9}$.

\section{Clouds}

Arctic clouds warm the surface via enhanced downwelling longwave radiation for much of the year, except during the summer months when the shortwave cloud radiative effect dominates, cooling the surface ${ }^{10}$. Due to the significant cloud radiative effects, changes in cloud amount or optical properties constitute a potentially important and uncertain feedback on AA. For instance, results from the Fifth Coupled Model Intercomparison Project (CMIP5) climate models disagree about whether Arctic cloud changes dampen or amplify $\mathrm{AA}^{11}$. A potentially important process contributing to Arctic cloud feedback is the cloud response to Arctic sea ice declines in response to increased surface turbulent heat and moisture fluxes. Recent observational evidence points to a significant cloud response to sea ice decline in fall, constituting a positive feedback that increases downwelling longwave radiation supporting a delayed sea ice freeze onset ${ }^{10}$. In contrast, in summer there is no significant cloud response, which would enhance reflected shortwave radiation and be a negative feedback on Arctic warming. Overall, state-of-the-art CMIP5 climate models point to a small positive cloud contribution to AA, primarily in fall and winter ${ }^{6}$. 


\section{Longwave Radiation}

Downward longwave radiation has also been identified as an important contributor to $\mathrm{AA}^{12,13,14}$. Emerging evidence suggests that anomalous cloud cover and downward longwave radiation during winter can hinder sea ice growth, thus reducing Arctic sea ice cover the following summer ${ }^{15,16,17}$. The CMIP5 climate models indicate that changes in the downwelling clear-sky longwave flux from the atmosphere, rather than the surface albedo feedback, is the largest contributing factor to $\mathrm{AA}^{11}$. The downward longwave radiation trend is positive almost everywhere over the Arctic Ocean for all seasons (see Figure 3 from Cohen et al. ${ }^{18}$ ). Warm, moist air intrusion events and attendant cloud radiative forcing have been found to regularly occur in Arctic winter ${ }^{19,20}$ and generate significant downwelling longwave radiation anomalies at the surface ${ }^{21}$. And similar extreme moisture transport into the Arctic in spring has been found to play an important role in determining the minimum sea-ice extent in the following September ${ }^{22,23,24}$. Moisture transport is most pronounced through the North Atlantic pathway and is favored during blocking events in the Atlantic sector ${ }^{23}$.

\section{Tropical Convection}

Tropical convection may also play an important role in forcing AA via heat and moisture transports during the cold season when the strong subtropical jet is conducive for a convection-driven Rossby wave propagation. Tropical convection can excite moisture intrusion events and Arctic warming on inter-decadal time scales ${ }^{25,26,27}$. Furthermore, intraseasonal tropical convection also appears to influence daily Arctic surface temperature and sea ice concentration via the Madden-Julian Oscillation phase 5 in both summer and winter ${ }^{28,29,30}$. These heat and moisture transports are 
enhanced by poleward propagating Rossby waves, excited by the tropical convection, that constructively interfere with the climatological stationary eddies ${ }^{16,26,31}$.

\section{Regional Response of AA}

\section{Asia}

Over the past decade, there is increasing evidence of a dynamical pathway, beginning with negative sea ice and positive air temperature anomalies over the Barents-Kara Seas during autumn, linking to cold Central and Far East Asia temperatures in mid-to-late winter ${ }^{32,33}$.

In December and January, the additional oceanic heat and moisture release from newly open waters in the Arctic Ocean to the atmosphere can increase Siberian snow cover ${ }^{34}$. The increased snow cover may enhance continental cooling and troughing over East Asia while strengthening the Siberian high upstream over northwest Eurasia ${ }^{35}$. The anticyclonic anomaly is often centered over the Barents-Kara Seas and Ural regions, bringing cold air from the Arctic to central Asia, which extends southeastward owing to a strengthened Siberian High. This southward flow of Arctic air has been implicated in more frequent or intensified cold surges over East Asia in recent $\operatorname{decades}^{36,37}$.

\section{North America}

Potential connections between the North American Arctic and mid-latitude weather depend on the constructive or destructive interactions with locations of existing large-scale waves in the jet stream. Climatological waves during winter usually consist of a block or ridge of higher 
geopotential heights over the northeastern Pacific and Alaska and/or Greenland along with a trough of lower heights over central and eastern North America, although a great deal of interannual variability is common ${ }^{38}$. Of particular interest is the observed winter cooling trend in eastern North America since $1990^{1}$. Although this trend coincides with Arctic warming ${ }^{39,40,41}$, studies have also pointed to internal variability ${ }^{42}$ and influences from the tropical Pacific ${ }^{43,44}$. More recent work suggests a tropical response to Arctic warming that feeds back to the Arctic ${ }^{26}$.

The potential for the Arctic to influence eastern North America involves a modification and added persistence to the existing long-wave pattern. Higher regional Arctic geopotential heights increase the likelihood of Alaskan and/or Greenland blocks; further analyses suggest that these regional blocks are independent features ${ }^{42,45,46}$. The geopotential height ridge along the west coast of North America along with low heights over eastern North America are an amplification of the climatological late-autumn/early-winter wave pattern. The anomaly pattern over the North Atlantic Ocean exhibits a strong downstream storm track coincident with eastern North America cold events. While these historical teleconnections do not necessarily involve Arctic change ${ }^{39}$, recent temperature trends (1988/89-2014/15) suggest a winter connection between warm temperatures in the Chukchi Sea and cold spells in eastern North America. Similarly, recent studies found that regional positive sea surface temperature anomalies were linked to Greenland blocks and years of extreme late freeze conditions in Baffin Bay since 2006 $6^{45,46}$.

\section{Europe}

Variability in Europe's weather is principally associated with the North Atlantic Oscillation (NAO) and high-pressure cold air masses from the east. During negative NAO episodes, Greenland blocking tends to be associated with a southward displaced storm track across the eastern Atlantic, 
which favors cold winters in northwestern Europe ${ }^{47}$. Reduced sea ice in the Baffin Bay, Davis Strait and the Labrador Sea is related to stronger Greenland blocking, an equatorward shifted Jet Stream and colder temperatures across Northern Europe ${ }^{46}$. In addition, evidence of connectivity between Barents-Kara sea ice loss and winter weather in northern Europe has been reported ${ }^{33,48,49}$. Modeling experiments show a diversity of NAO responses to reduced Arctic sea ice. The atmospheric response is dependent on the $\operatorname{sign}^{49}$, the pattern ${ }^{50,14}$ and the amplitude $48,51,52,53$ of the sea ice anomalies.

\section{Summer}

While linkages in early winter have received the most attention by researchers owing to their influence on extreme winter weather, progress has also been made in understanding summer linkages. Here, there is an interaction of newly open water areas, atmospheric and oceanic frontal features, and phasing with high-amplitude/high-wavenumber atmospheric circulation features ${ }^{54,55}$. In addition, the loss of snow cover favors earlier and more intense heating of the land areas surrounding the Arctic ocean. This is consistent with the pattern of AA during summer as the regions of largest positive $1000-500 \mathrm{hPa}$ thickness anomalies occur mainly over land. This earlier onset of continental warming has been linked to more frequent extreme heat waves and persistent summer weather patterns ${ }^{55,56}$.

The summer season has seen an overall weakening of storm tracks over the last decades ${ }^{56}$ and this is also projected by model simulations of future climate change ${ }^{57,58}$. How a weakened flow might affect weather systems, their frequency and persistence, is not fully understood ${ }^{59}$. See Coumou et al. ${ }^{60}$ for a more in-depth review of summer linkages. 


\section{Summer vs. Winter Forecasts}

As seen in Figure 4 the NMME winter temperature forecasts are diverging to the warm side from the observed winter temperatures across the mid-latitude continents. In Supplementary Figure 11 we present the analogous of Figure 4 but for summer. In contrast to winter, the NMME summer temperature trend is nearly parallel to the observed summer trend across the mid-latitude continents despite the cold bias. It is pertinent to our understanding of AA mid-latitude linkages as to why the model simulated temperature trends diverge from the observations across the midlatitude continents in winter but not in summer.

A rare observational analysis outlier argued that AA does not force colder winter temperatures across the mid-latitude continents ${ }^{61}$. The authors, based on turbulent heat fluxes (sensible plus latent heat flux or THF), differentiated between winter seasons when the Arctic ocean forced the atmosphere and when the atmosphere forced the Arctic ocean. Those winters when sea ice was low (high) and the anomalous THF is upward (downward) then the Arctic ocean is forcing the atmosphere and when sea ice was low (high) and the anomalous THF is downward (upward) then the atmosphere is forcing the Arctic ocean. They then showed that the warm Arctic/cold continent (WACC) pattern only exists when the atmosphere is forcing the Arctic Ocean but when the Arctic Ocean is forcing the atmosphere, the Arctic is warm but the continents are no longer cold.

Whether the winters were divided into atmosphere forcing the ocean or vice versa the net THF anomaly was always negative or downward, which indicates a net heating of the ocean but a net cooling of the atmosphere. Therefore, that the atmosphere was relatively warm in all cases, likely indicates that the analysis is not in energy balance, especially for those winters where the ocean forces the atmosphere since the anomalies were an order of magnitude larger than when the atmosphere forces the ocean. 
A cleaner comparison is to take the difference between summer and winter. In winter the absolute THF value is positive or upward and the difference between THF in summer and winter is negative or downward (as well as the difference in the trends) especially over open water ${ }^{6}$. In Supplementary Figure 12a we show the differences in temperature trends between summer and winter, where the THF are negative in the absolute sense and represents the atmosphere forcing the ocean. For summer minus winter the differences in the temperature trends during the period of AA or strong sea ice melt, the Arctic is relatively cold, and the mid-latitudes are relatively warm. In Supplementary Figure 12b we show the differences in temperature trends between winter and summer, where the THF are positive in the absolute sense and represents the ocean forcing the atmosphere. For winter minus summer, the Arctic is relatively warm, and the mid-latitudes are relatively cold. Importantly in this analysis, the Arctic temperatures are consistent with the sign of the THF difference, indicating that the analysis is in energy balance. Based on the THF summer and winter difference only, the warm Arctic and cold continents pattern only exists for when the Arctic ocean is forcing the atmosphere and not vice versa. 
Winter Mean Surface Temperature Anomalies
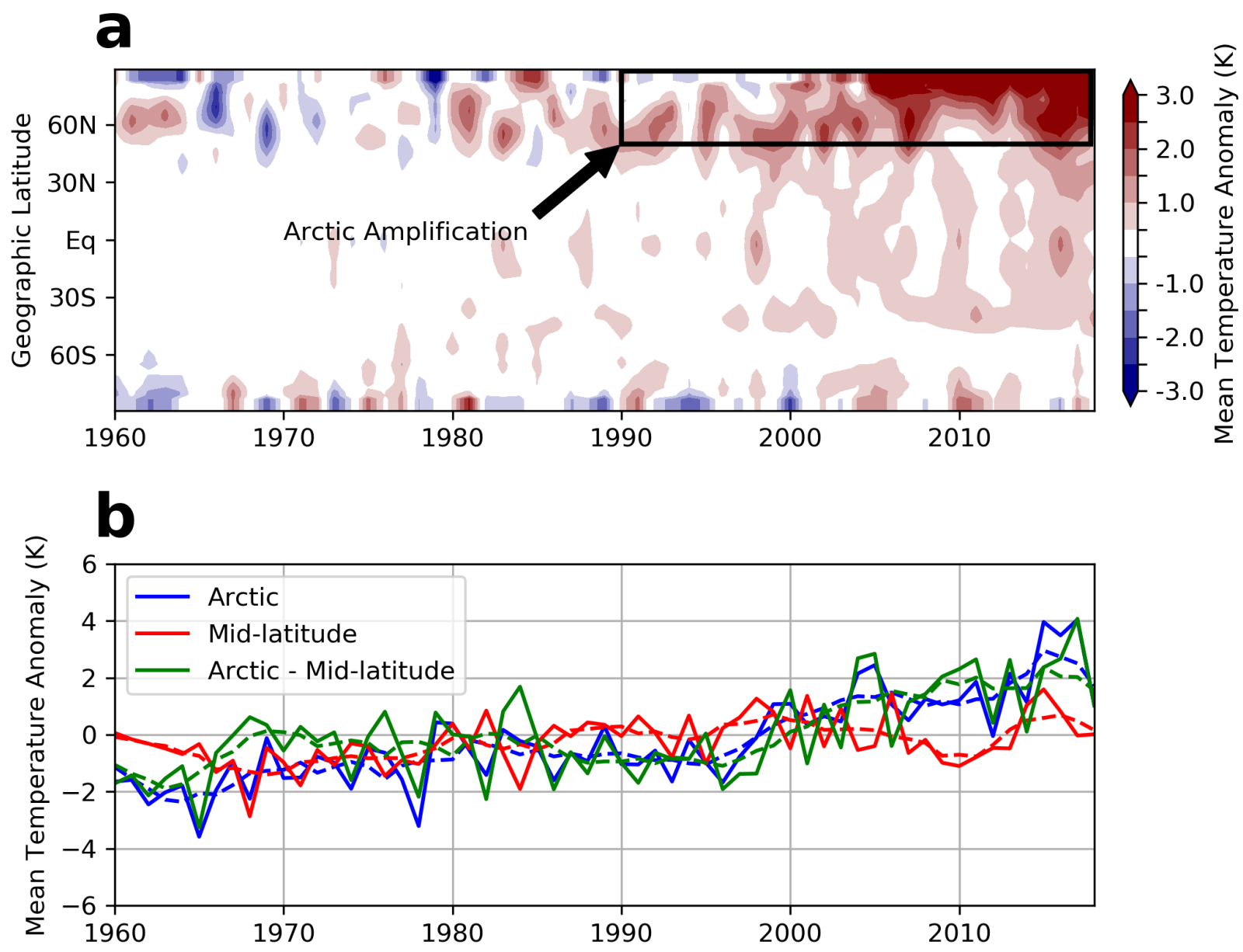

Supplementary Figure 1. Arctic amplification is increasing. a Mean temperature (averaged for December, January, and February), shown as anomaly from 1951-1980 mean temperatures. The area inside the black box shows the amplified warming in the Arctic. Updated from Wendisch et al. ${ }^{62}$ and data are provided by the NASA Goddard Institute for Space Studies. b Interannual (solid) and five-year running mean (dashed) of the temperature anomaly time series of December, January and February Arctic $\left(60-90^{\circ} \mathrm{N}\right.$; blue), mid-latitude land only $\left(30-60^{\circ} \mathrm{N}\right.$; red), and the difference between Arctic and mid-latitude area averaged temperatures (green). Climatology used based on 1981-2010 means. Data is from the NCEP/NCAR reanalysis. Both plots cover data from 1960 through 2019. 

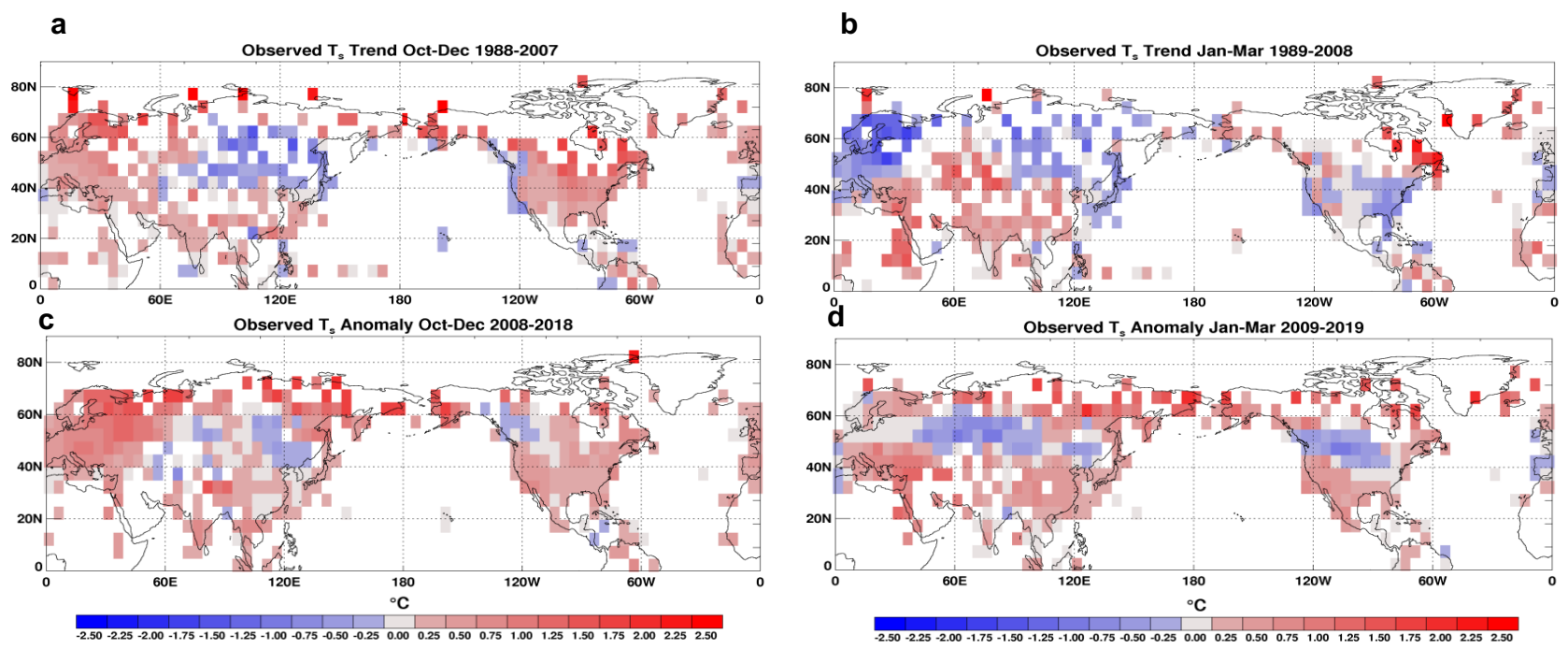

\section{Supplementary Figure 2. Recent pattern of warming and cooling across NH consistent with}

earlier trends. a The decadal trend in October, November and December 2-m air temperatures over land surface 1988-2007. b The decadal trend in January, February and March 2-m air temperatures over land surface 1989-2008. c The average seasonal anomaly for October, November and December 2-m air temperatures over land surface 2008-2018. d The average seasonal anomaly for January, February and March 2-m air temperatures over land surface 20092019. Colored shading in degrees Celsius; values between -0.25 and 0.25 are shown in gray and missing and ocean values are shown in white. Climatology used in all plots are 1981-2010 means. Data is land station data from the Hadley Centre Climate Risk Unit ${ }^{63}$. 

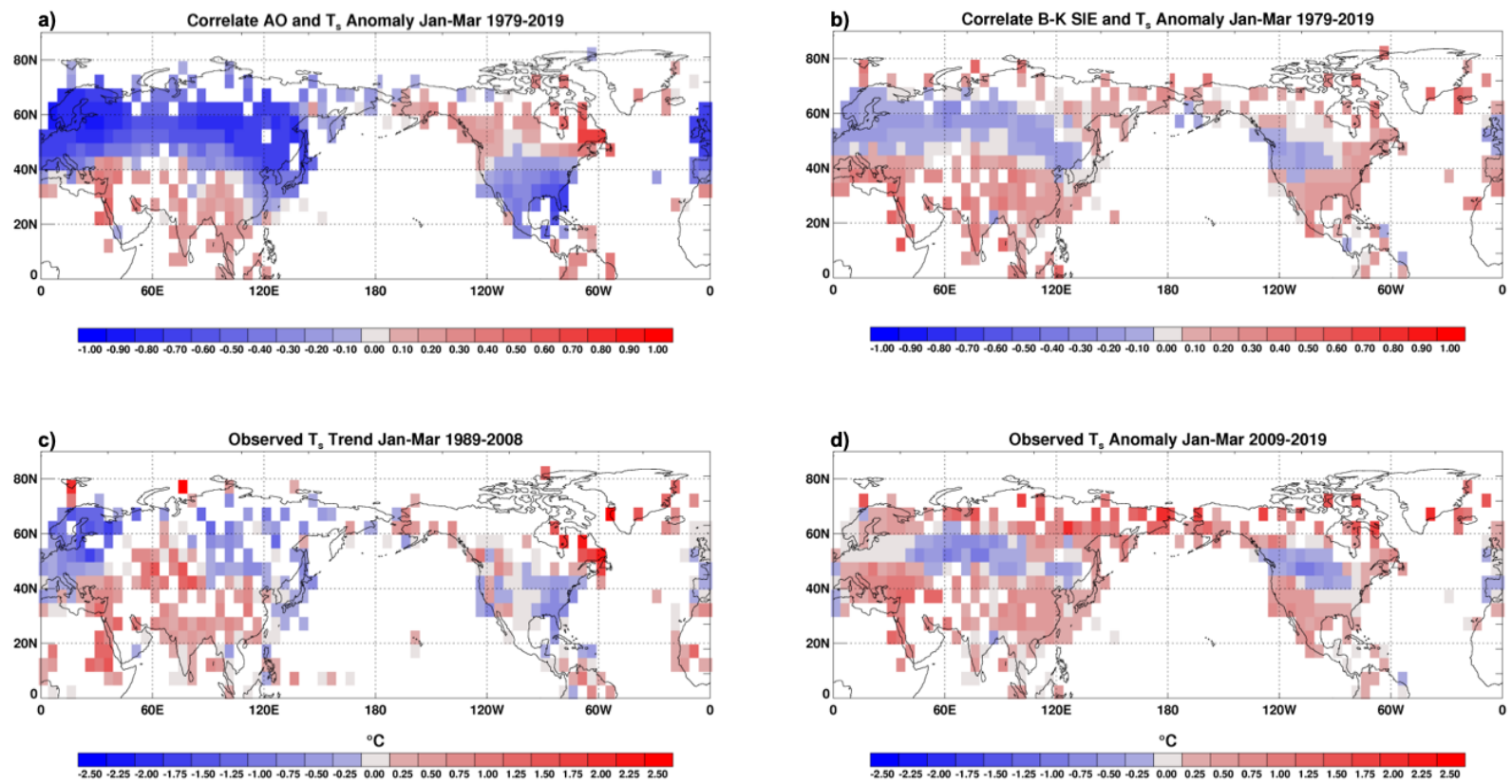

Supplementary Figure 3. NH temperature is shifting from AO to sea ice pattern of variability. a The correlation between the January, February and March Arctic Oscillation and January, February and March 2-m air temperatures over land surface 1979-2019. b The correlation between November Barents-Kara sea ice extent 1978-2018 and January, February and March 2-m air temperatures over land surface 1979-2019. c The decadal trend in January, February and March 2-m air temperatures over land surface 1989-2008. d The average seasonal anomaly for January, February and March 2-m air temperatures over land surface 2009-2019. Climatology used in all plots are 1981-2010 means. Data is land station data from the Hadley Centre Climate Risk Unit ${ }^{63}$. 


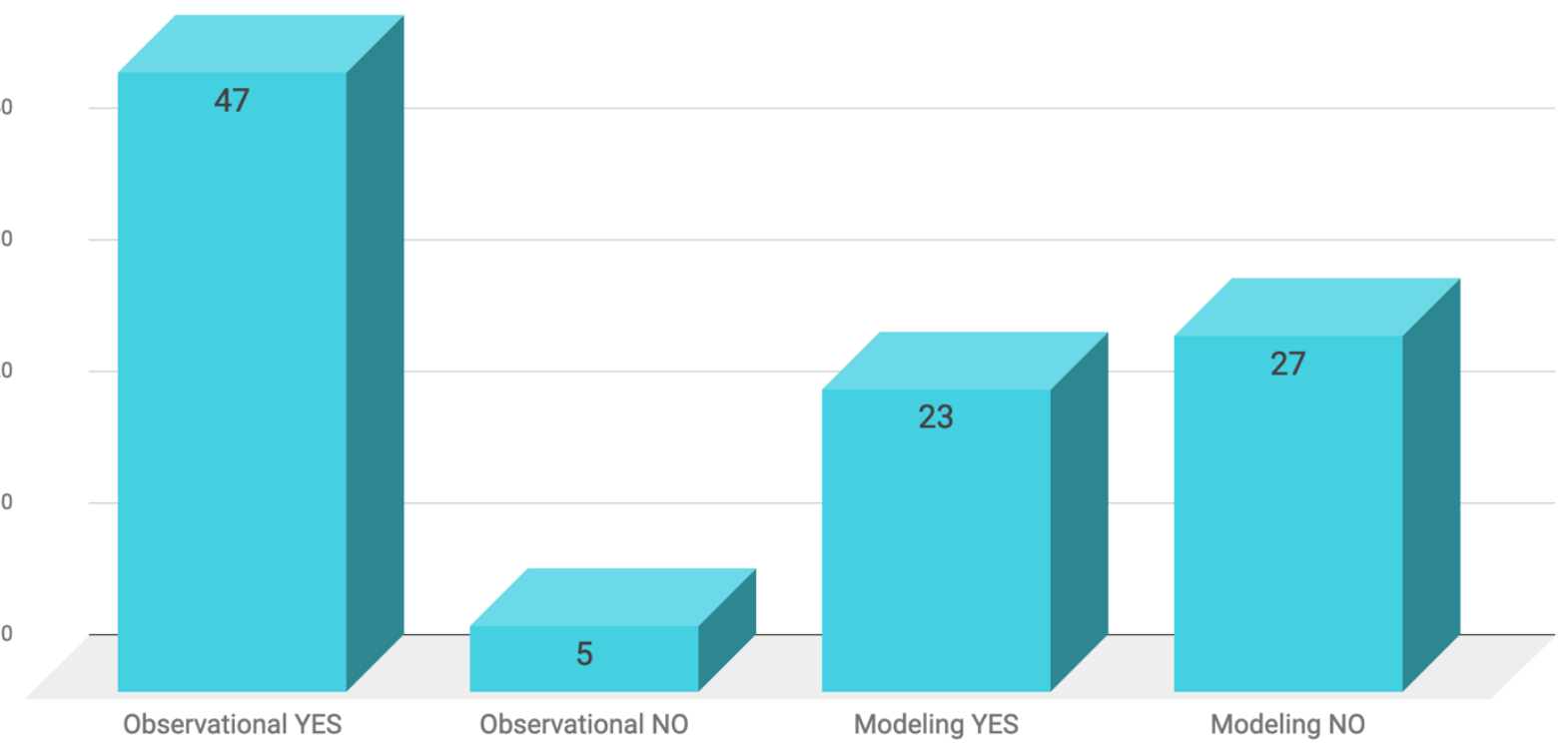

Supplementary Figure 4. Studies arguing for and against a link between AA and an increase in severe winter weather are divided. Number of observational/modeling studies that support AA is linked with an increase in severe winter weather and observational/modeling studies that support AA is not linked with an increase in severe winter weather. A list of the studies behind the bar graph can be found here: List of Studies. 


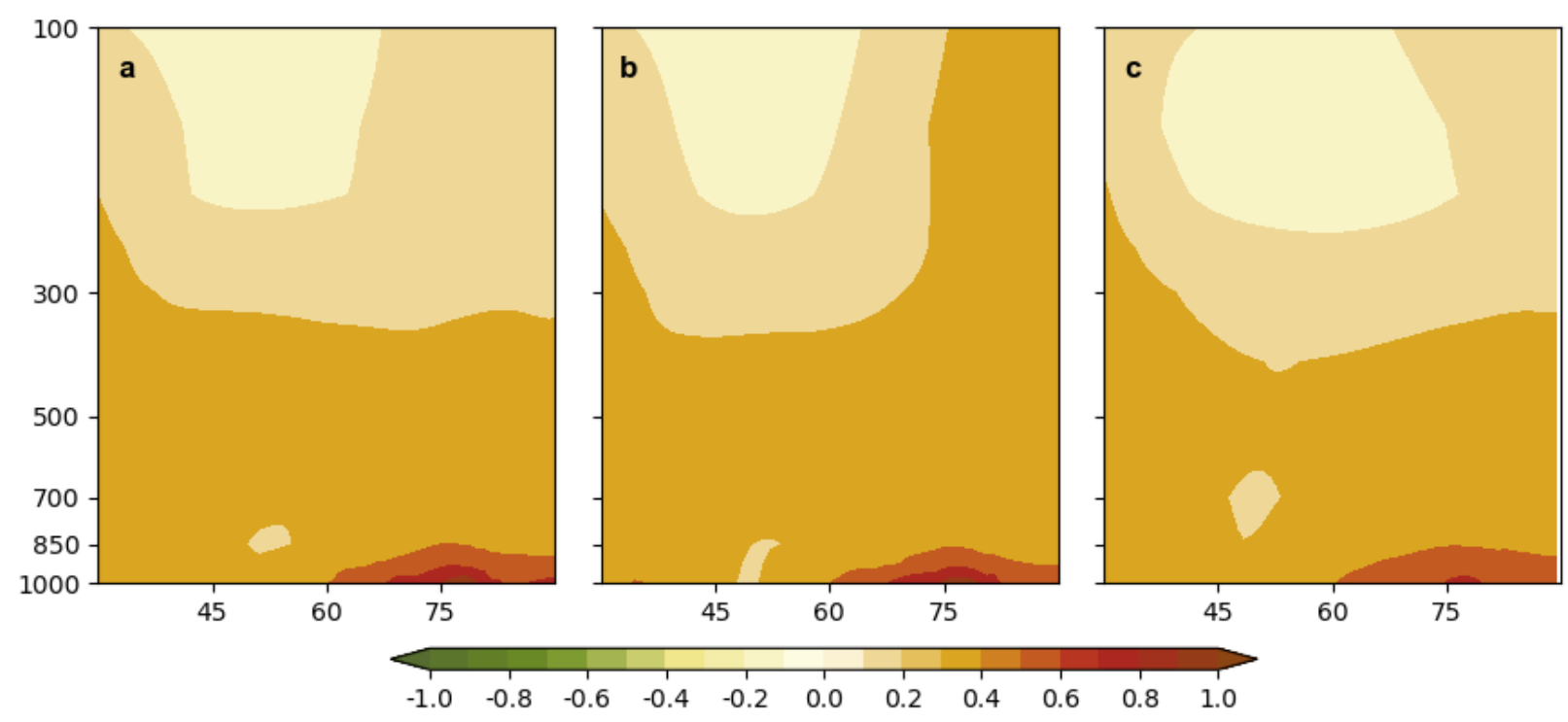

Supplementary Figure 5. Simulated temperature trends consistent among model experiments. Seasonal and zonal-mean air temperature trends in degrees Celsius per decade from 1981-2015 for the average of ensemble members for a Community Atmosphere Model (low top), b Community Atmosphere Model (high top), and c ECHAM model. 

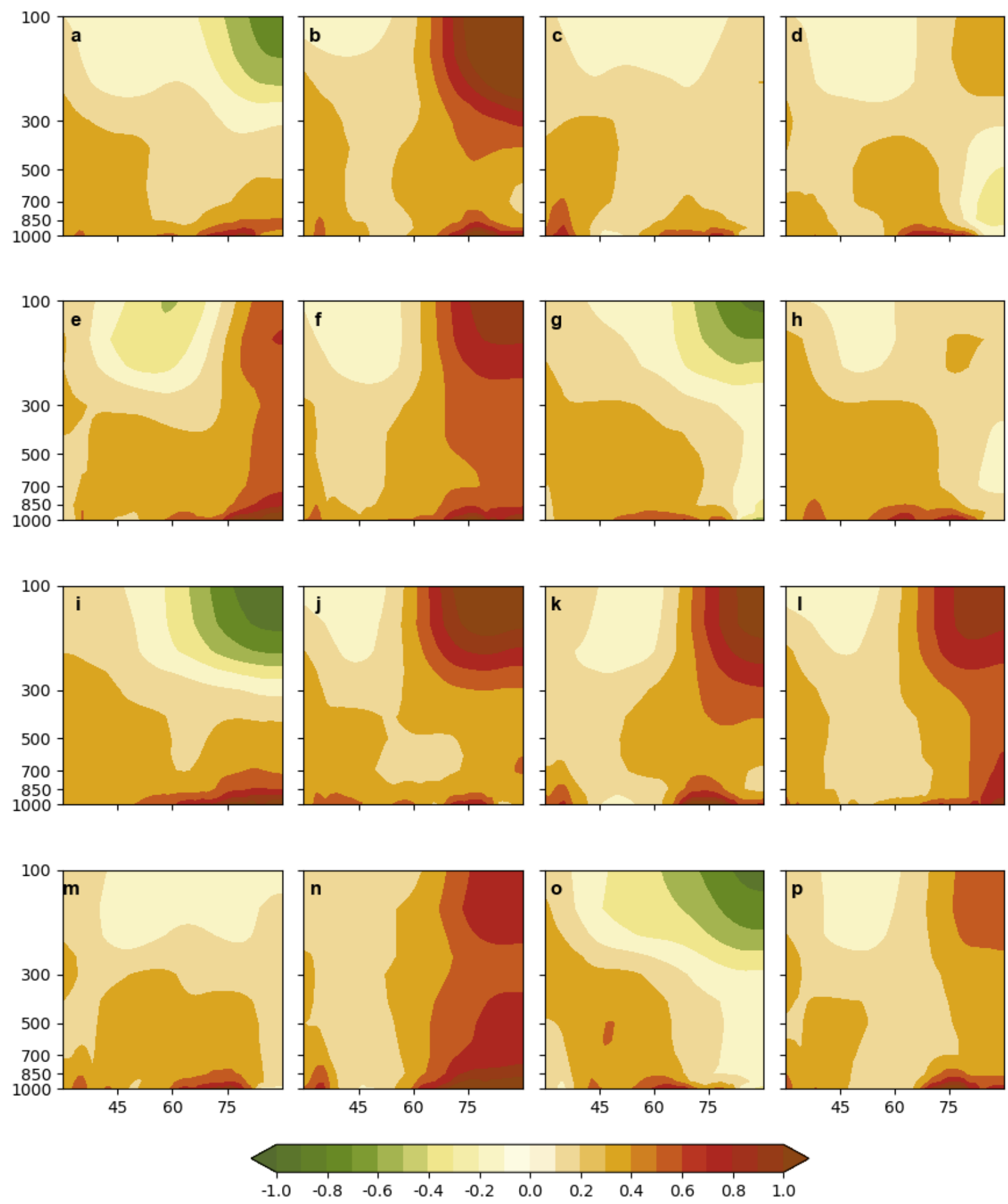

Supplementary Figure 6. Simulated temperature trends vary greatly among ensemble members. Seasonal and zonal-mean air temperature trends in degrees Celsius per decade from 1981-2015 for 16 (a - p) ensemble members of the Community Atmosphere Model (high top). 


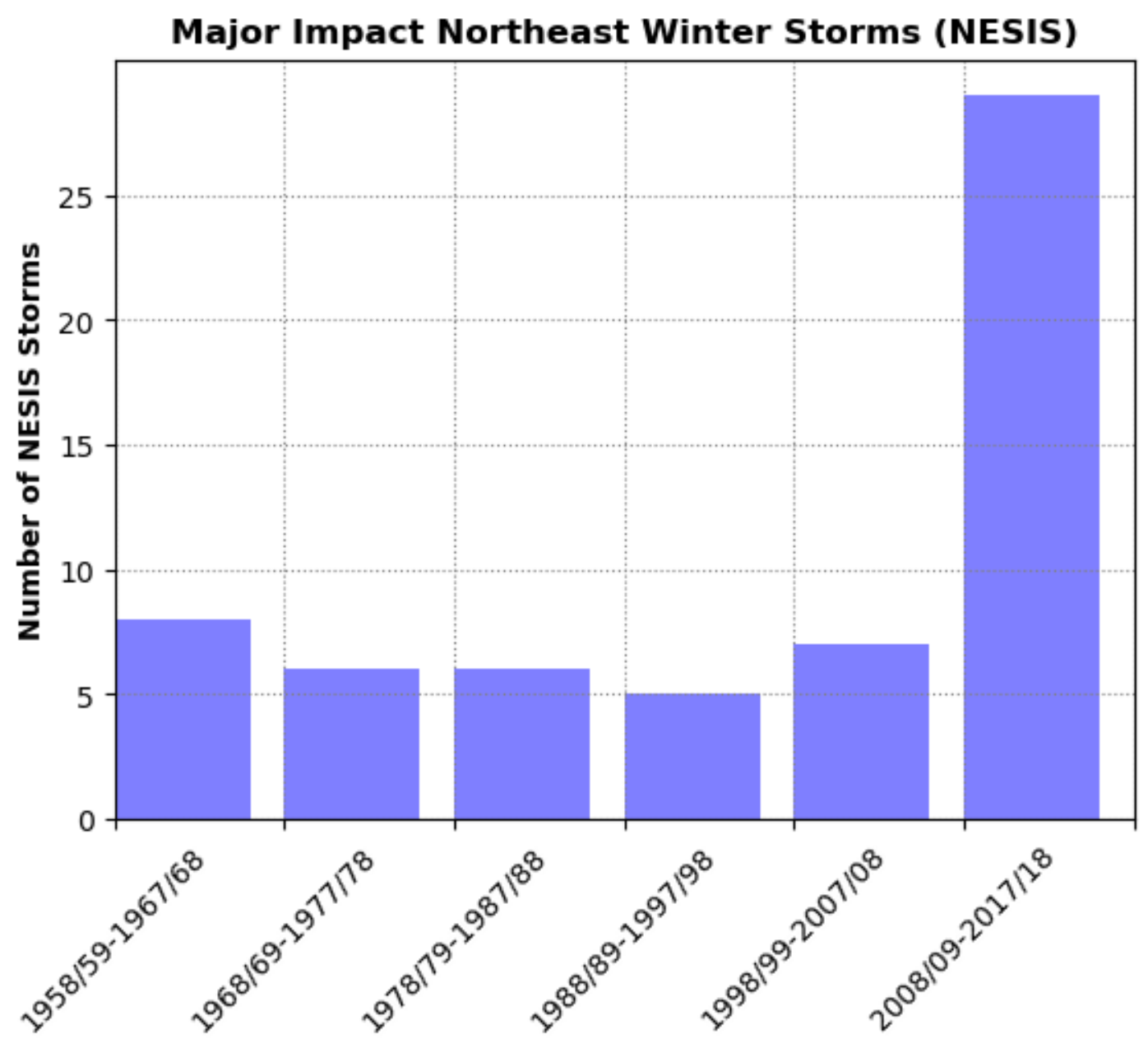

Supplementary Figure 7. Impactful Northeast US snowstorms tripled over the past decade.

Number of impactful snowstorms in the Northeastern US is triple in number over the most recent decade compared to all previous decades. The number of major impact Northeastern US winter storms referred to as Northeast Snowfall Impact Scale (NESIS) per decade starting from winter 1958/59. Data available from NOAA https://www.ncdc.noaa.gov/snow-and-ice/rsi/nesis. 

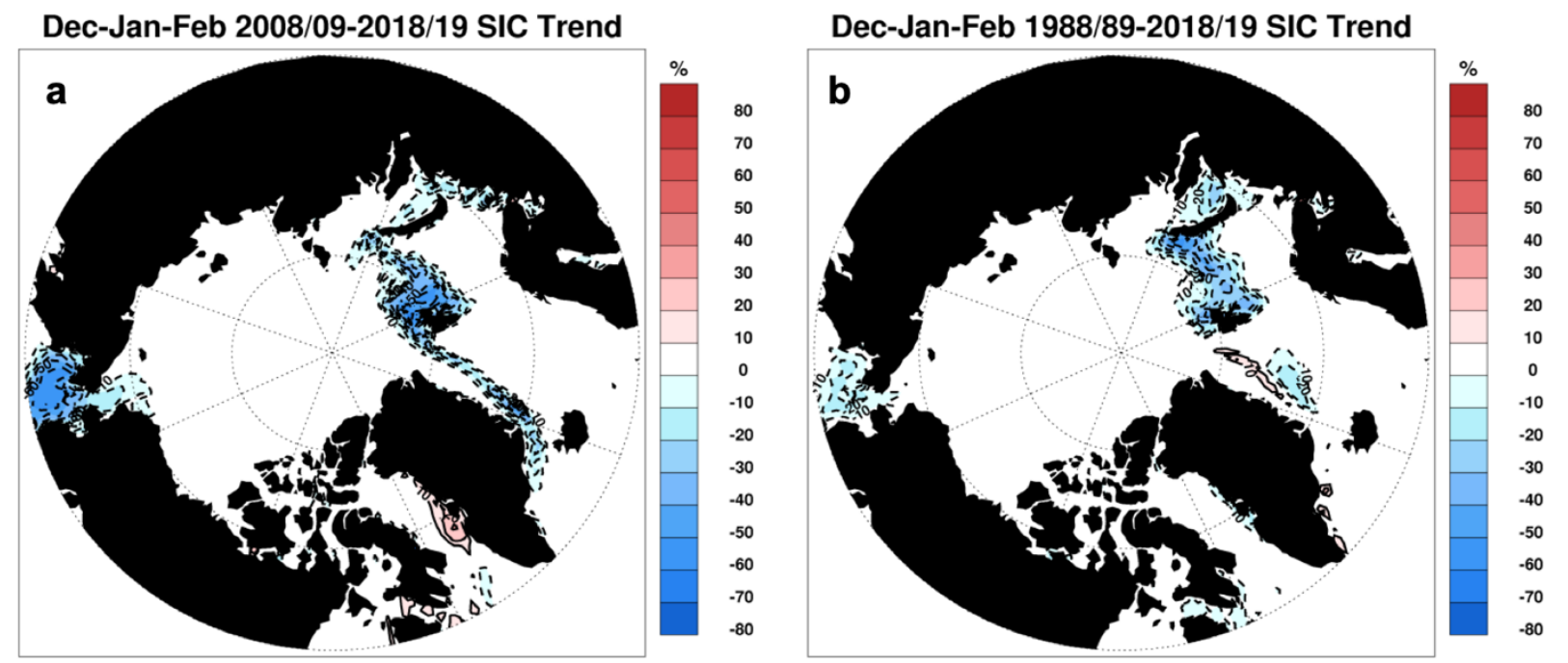

Supplementary Figure 8. Sea ice loss is greatest in Barents-Kara, Chukchi-Bering Seas and around Greenland. a Linear decadal-trends in winter Arctic sea ice concentration from 2008/09 through 2017/18 (multiplied by 100). b Linear trends in winter Arctic sea ice concentration from 1988/89 through 2017/18 (multiplied by 200). 

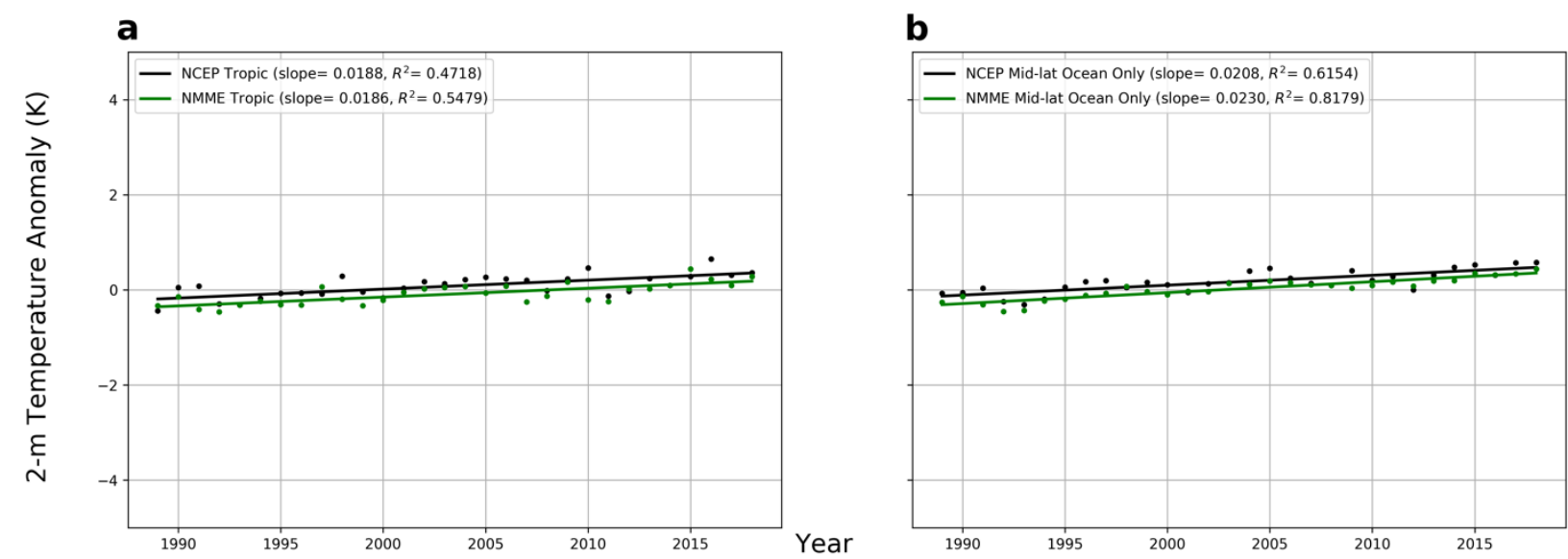

Supplementary Figure 9. Observed and simulated warming match in the tropics and mid-

latitude oceans. a Reanalysis (black) and hindcasted/predicted NMME ensemble mean (green)

$\mathrm{NH}$ tropical 2-meter temperature anomalies and linear trends. b Reanalysis (black) and hindcasted/predicted NH NMME ensemble mean (green) mid-latitude ocean 2-meter temperature anomalies and linear trends. All plots for December, January, February and March from 1988 through 2019 and climatology used for reanalysis is 1981-2010 and for NMME is 1982-2010 winter mean respectively. Variance $\left(\mathrm{R}^{2}\right)$ included for all trend lines. All trends are statistically significant at the $>99 \%$ confidence level. 

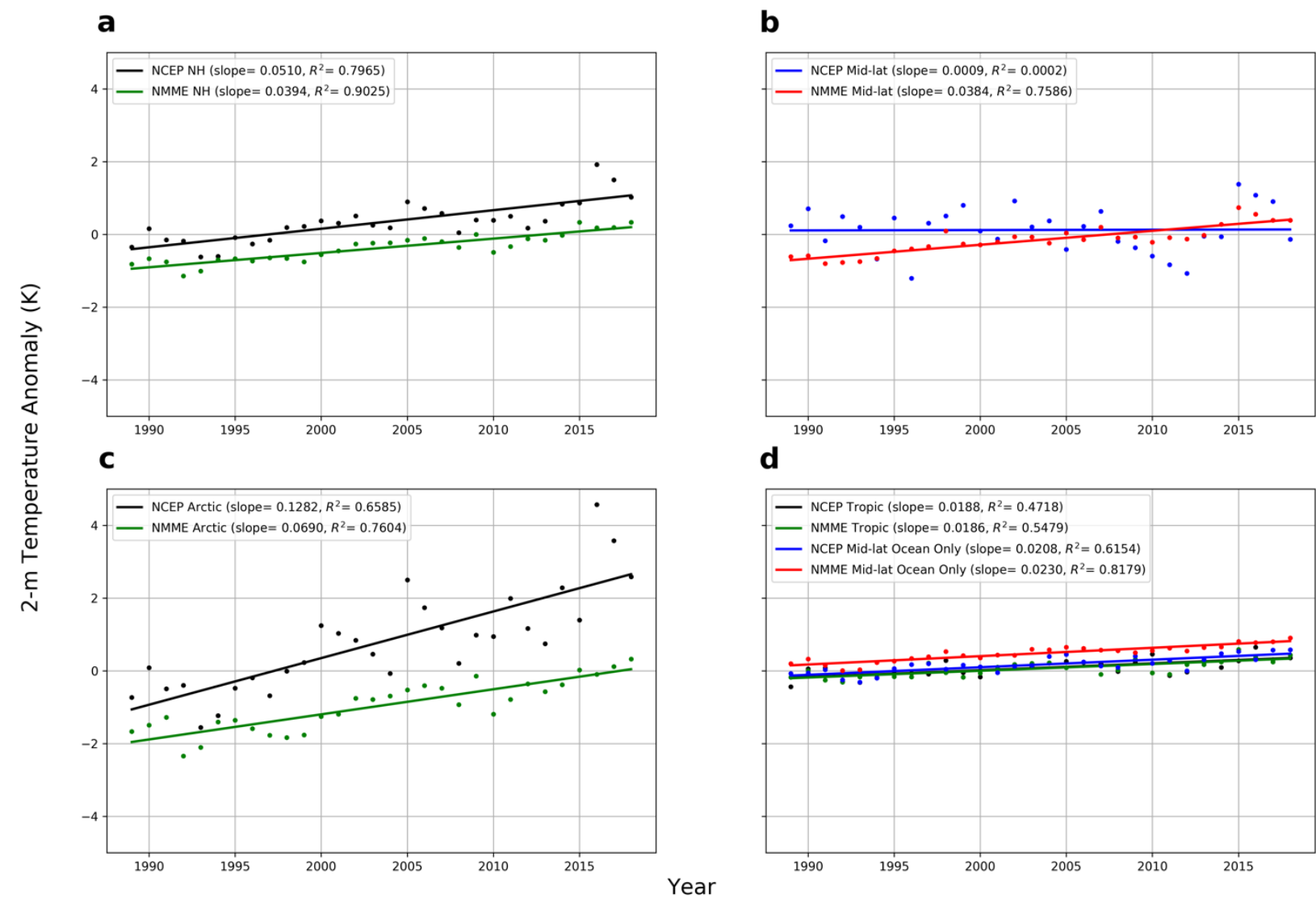

d

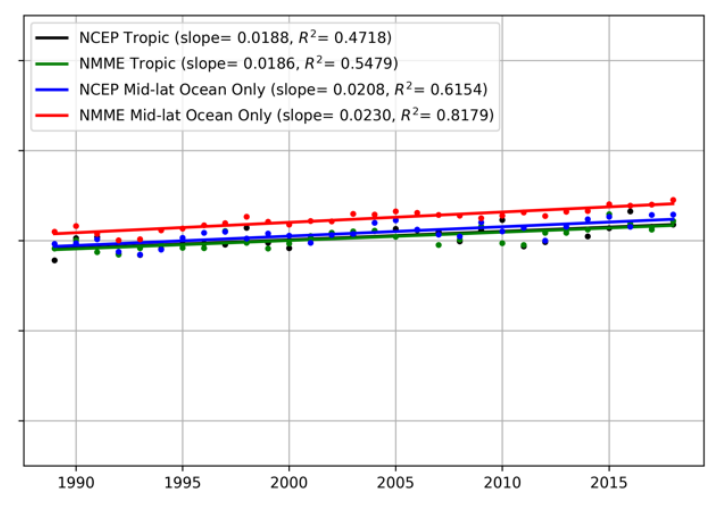

Supplementary Figure 10. NH warming trends are insensitive to climatology. a Reanalysis (black) and hindcasted/predicted NMME ensemble mean (green) NH temperature anomalies (black) and linear trends. b Reanalysis (blue) and hindcasted/predicted NMME ensemble mean (red) NH continental mid-latitude temperature anomalies and linear trends. c Reanalysis (black) and hindcasted/predicted NMME ensemble mean (green) Arctic temperature anomalies and linear trends. d Reanalysis (black) and hindcasted/predicted NMME ensemble mean (green) NH tropical 2-meter temperature anomalies and reanalysis (blue) and hindcasted/predicted NH NMME ensemble mean (red) mid-latitude ocean 2-meter temperature anomalies and linear trends. All plots for December, January, February and March from 1988 through 2019 and climatology used is 1981-2010 winter mean from reanalysis only. Variance $\left(\mathrm{R}^{2}\right)$ included for all trend lines. All 
trends except the NCEP mid-latitude land regions are statistically significant at the $>99 \%$ confidence level. 
JJA analysis
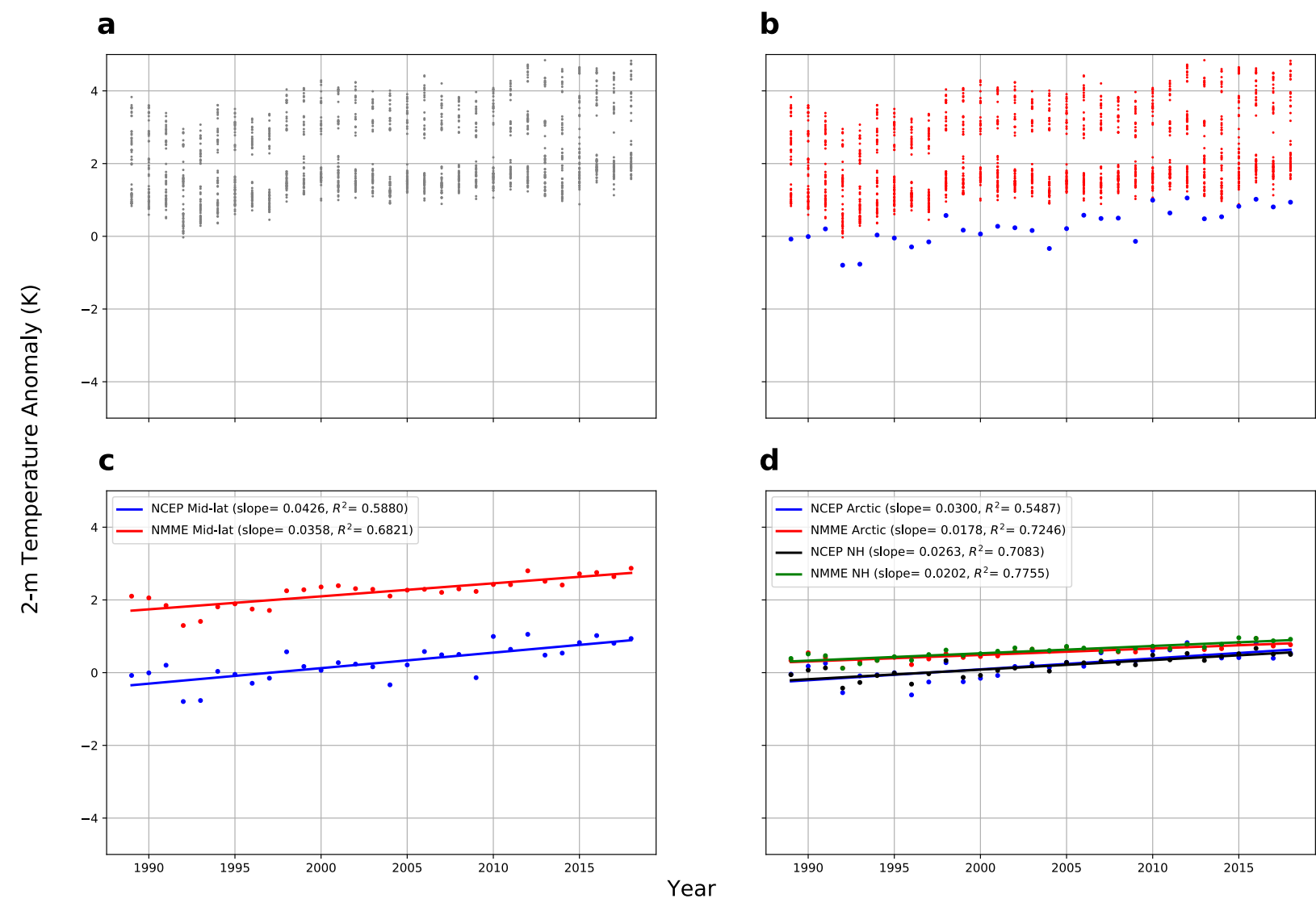

d

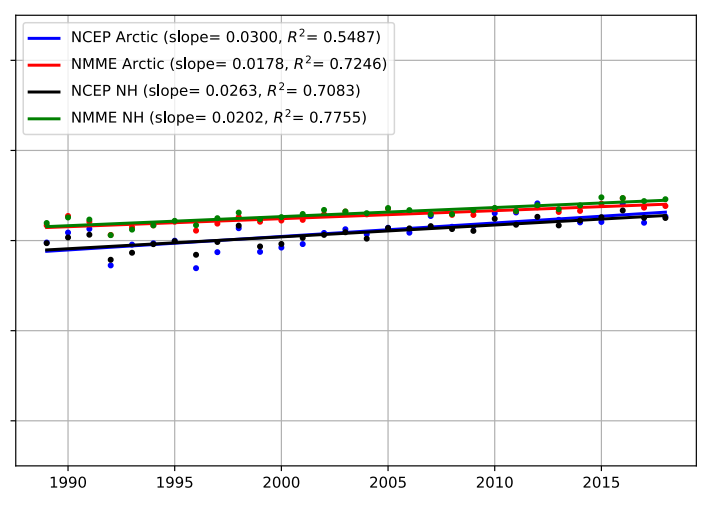

Supplementary Figure 11. Observed and simulated Arctic and mid-latitude summer temperature trends are parallel. a Reanalysis and hindcasted/predicted NMME individual ensemble members for NH mid-latitude continental temperature anomalies. b Same as a but reanalysis (blue) and NMME (red). c Reanalysis (blue) and hindcasted/predicted NMME ensemble mean (red) NH mid-latitude continental temperature anomalies. Also included is the linear trend line for each dataset. $\mathbf{d}$ Reanalysis (black) and hindcasted/predicted NMME ensemble mean (green) NH temperature anomalies and reanalysis (blue) and hindcasted/predicted NMME ensemble mean (red) Arctic temperature anomalies and linear trends. All temperature anomalies are for June, July and August from 1989 through 2018. Anomalies are calculated relative to climatology from reanalysis 1981-2010 and from NMME 1982-2010 summer mean respectively. 
Variance $\left(\mathrm{R}^{2}\right)$ included for all trend lines. All trends except the NCEP NH mid-latitude land regions are statistically significant at the $>99 \%$ confidence level. 

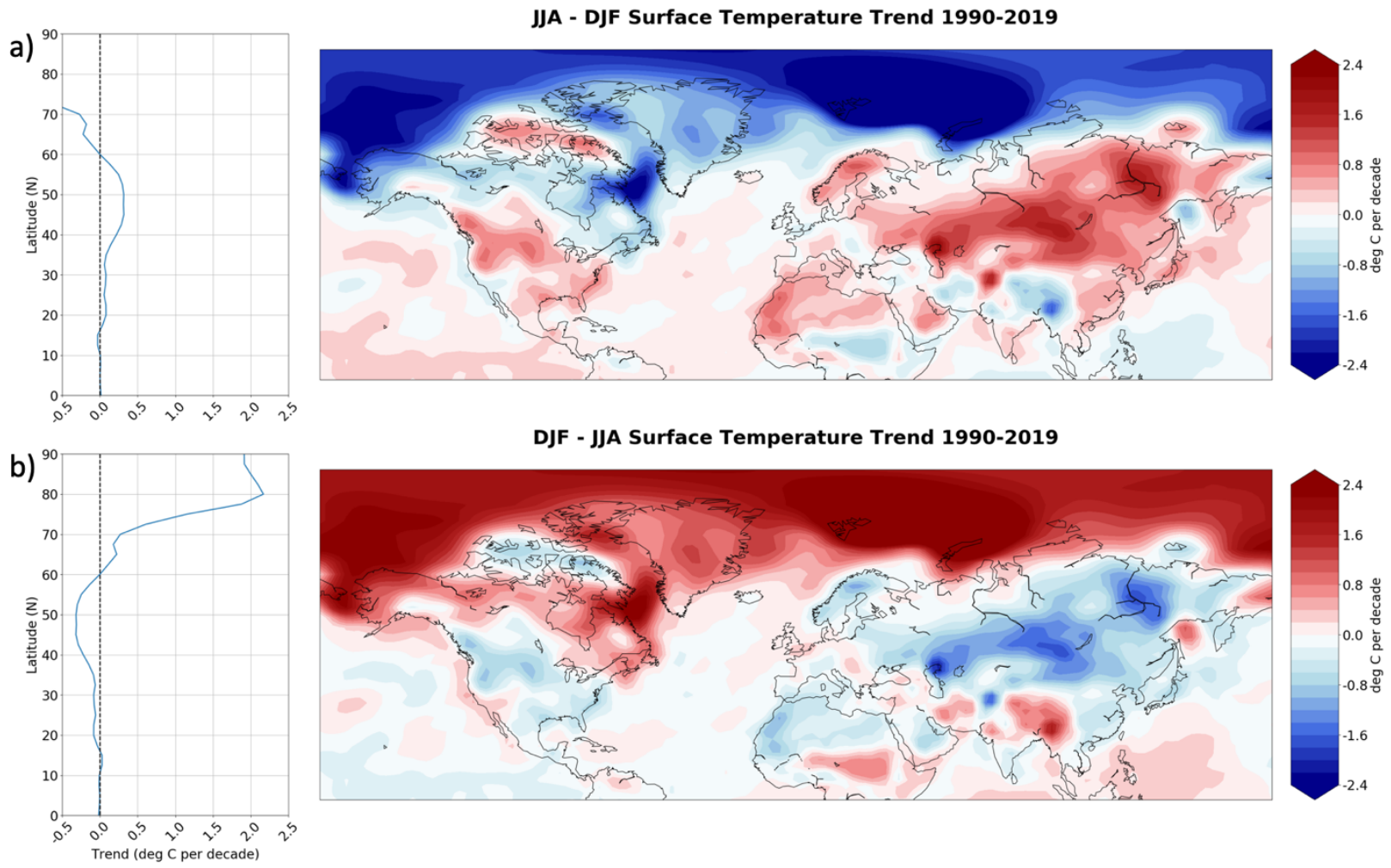

DJF - JJA Surface Temperature Trend 1990-2019

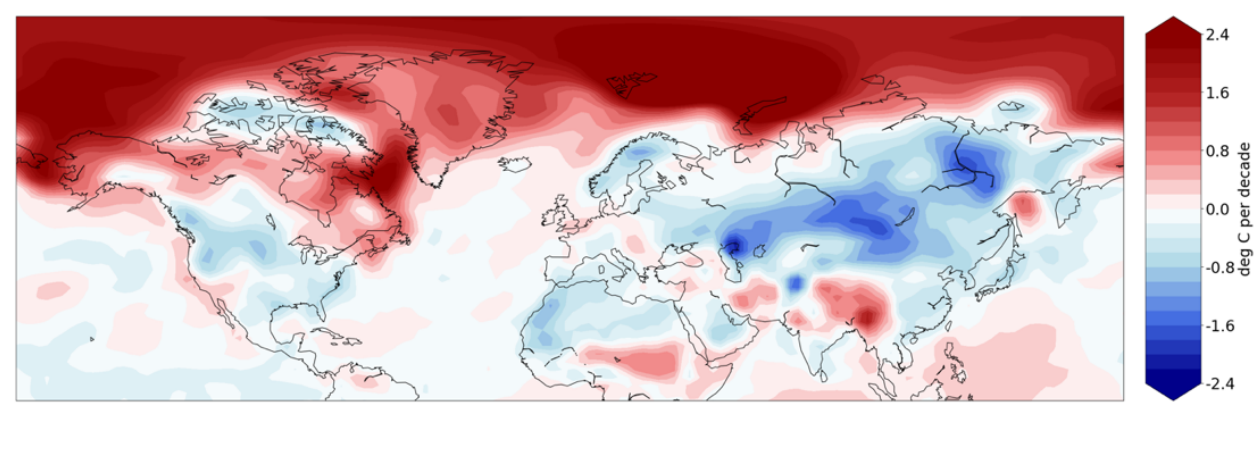

Supplementary Figure 12. Summer minus winter temperature trends and vice versa are consistent with warm Arctic-cold continents pattern. a Summer minus winter temperature trends from 1990 through 2019 show a relatively cold Arctic and warm midlatitudes. Temperature trend difference by latitude shown on the right. b Same as a but for winter minus summer temperature trends. Data taken from NCEP/NCAR reanalysis. 
Supplementary Table 1. List of coupled climate models from the CMIP5 model archive analyzed in this study.

\begin{tabular}{|c|c|}
\hline Institute & model \\
\hline \multirow{3}{*}{$\begin{array}{l}\text { National Aeronautics and Space Administration (NASA) Goddard Institute for } \\
\text { Space Studies (GISS), United States of America }\end{array}$} & GISS-E2-R-CC \\
\hline & GISS-E2-R \\
\hline & GISS-E2-H-CC \\
\hline EC-EARTH consortium & EC-EARTH \\
\hline $\begin{array}{l}\text { Centre National de Recherches Météorologiques/Centre Européen de Recherche } \\
\text { et Formation Avancées en Calcul Scientifique (CNRM-CERFACS), France }\end{array}$ & CNRM-CM5 \\
\hline National Institute of Meteorological Research/Korea Meteorological Administration & HadGEM2-AO \\
\hline \multirow[t]{2}{*}{ Max Planck Institute for Meteorology (MPI-M), Germany } & MPI-ESM-MR \\
\hline & MPI-ESM-LR \\
\hline Beijing Normal University (BNU), China & BNU-ESM \\
\hline $\begin{array}{l}\text { Commonwealth Scientific and Industrial Research Organisation (CSIRO) in } \\
\text { collaboration with the Queensland Climate Change Centre of Excellence (QCCCE), } \\
\text { Australia }\end{array}$ & CSIRO-Mk3.6.0 \\
\hline \multirow[t]{3}{*}{ Institut Pierre-Simon Laplace } & IPSL-CM5A-LR \\
\hline & IPSL-CM5B-LR \\
\hline & IPSL-CM5A-MR \\
\hline National Center for Atmospheric Research (NCAR), United States & CCSM4 \\
\hline \multirow{2}{*}{$\begin{array}{l}\text { Met Office Hadley Centre (additional HadGEM2-ES realizations contributed by } \\
\text { Instituto Nacional de Pesquisas Espaciais) }\end{array}$} & HadGEM2-ES \\
\hline & HadGEM2-CC \\
\hline Institute of Numerical Mathematics (INM), Russia & INM-CM4 \\
\hline \multirow{3}{*}{$\begin{array}{l}\text { Atmosphere and Ocean Research Institute (The University of Tokyo)/National } \\
\text { Institute for Environmental Studies/Japan Agency for Marine-Earth Science and } \\
\text { Technology, Japan }\end{array}$} & MIROC5 \\
\hline & $\begin{array}{l}\text { MIROC-ESM- } \\
\text { CHEM }\end{array}$ \\
\hline & MIROC-ESM \\
\hline \multirow[t]{3}{*}{ National Center for Atmospheric Research (NCAR), United States } & CESM1I(WACCMI) \\
\hline & CESM1I(CAM5】) \\
\hline & CESM1 (BGCI) \\
\hline Canadian Centre for Climate Modeling and Analysis (CCCma), Canada & CanESM2 \\
\hline Institute of Atmospheric Physics, Chinese Academy of Sciences & FGOALS-s2 \\
\hline $\begin{array}{l}\text { National Oceanic and Atmospheric Adminisrtation (NOAA)- Geophysical Fluid } \\
\text { Dynamics Laboratory }\end{array}$ & GFDL-CM3 \\
\hline
\end{tabular}




\begin{tabular}{|l|l|}
\hline Norwegian Climate Centre (NCC), Norway & NorESM1-M \\
\hline & NorESM1-ME \\
\hline The First Institute of Oceanography, SOA, China & FIO-ESM \\
\hline Beijing Climate Center (BCC), China & BCC-CSM1.1 (mI) \\
\hline & BCC-CSM1.1 \\
\hline $\begin{array}{l}\text { CSIRO (Commonwealth Scientific and Industrial Research Organisation, Australia), } \\
\text { and BOM (Bureau of Meteorology, Australia) }\end{array}$ & ACCESS1.3 \\
\hline & ACCESS1.0 \\
\hline Meteorological Research Institute (MRI), Japan & MRI-CGCM3 \\
\hline Centro Euro-Mediterraneo per I Cambiamenti Climatici & CMCC-CM \\
\hline & CMCC-CMS \\
\hline & CMCC-CESM \\
\hline Institute of Atmospheric Physics (IAP) and Tsinghua University, China & FGOALS-g2 \\
\hline
\end{tabular}




\section{References}

1. Cohen, J. et al. Recent Arctic amplification and extreme mid-latitude weather. Nat. Geosci. 7, 627-637, https://doi.org/10.1038/ngeo2234 (2014).

2. Horton, R. et al. Contribution of changes in atmospheric circulation patterns to extreme temperature trends. Nature 522, 465-469 https:// doi.org/10.1038/nature14550 (2015).

3. Kwok, R. et al. Thinning and volume loss of the Arctic Ocean sea ice cover: 2003-2008. J. Geophys. Res. 114, https://doi.org/10.1029/2009JC005312 (2009).

4. Lang, A., Yang, S. \& Kass, E. Sea ice thickness and recent Arctic warming. Geophys. Res. Lett. 44, 409-418, https://doi.org/10.1002/2016GL071274 (2017).

5. Stroeve, J. C., Markus, T., Boisvert, L., Miller, J. \& Barrett, A. Changes in Arctic melt season and implications for sea ice loss. Geophys. Res. Lett. 41, 1216-1225, https://doi.org/10.1002/2013GL058951 (2014).

6. Taylor, P. C., Hegyi, B. M., Boeke, R. C. \& Boisvert, L. N. On the increasing importance of air-sea exchanges in a thawing Arctic: A review. Atmos. 9, https://doi.org/10.3390/atmos9020041 (2018).

7. Ding, Q. et al. Influence of high-latitude atmospheric circulation changes on summertime Arctic sea ice. Nat. Clim. Change 7, 289-295, https://doi.org/10.1038/NCLIMATE3241 (2017).

8. Serreze, M. C. \& Francis, J. A. The arctic amplification debate. Climatic Change 76(3-4), 241-264, https://doi.org/1007/s10584-005-9017-y (2006).

9. Screen, J. A. \& Simmonds, I. The central role of diminishing sea ice in recent Arctic temperature amplification. Nature 464, 1334-1337, https://doi.org/10.1038/nature09051 (2010). 
10. Kay, J. E. \& L'Ecuyer, T. Observational constraints on Arctic ocean clouds and radiative fluxes during the early $21^{\text {st }}$ century. J. Geophys. Res. Atmos. 118, 7219-7236, https://doi:10.1002/jgrd.50489 (2013).

11. Boeke, R. C. \& Taylor, P. C. Seasonal energy exchange in sea ice retreat regions contributes to differences in projected Arctic warming. Nature Comm. 9, 5017, https://doi:10.1038/s41467-018-07061-9 (2018).

12. Uttal, T. et al. Surface heat budget of the Arctic Ocean. Bull. Amer. Meteor. Soc. 83, 255275, https://doi:10.1175/1520-0477(2002)083<0255:SHBOTA>2.3.CO;2 (2002).

13. Francis, J. A., Hunter, E., Key, J. R. \& Wang, X. Clues to variability in Arctic minimum sea ice extent. Geophys. Res. Lett. 32, https://doi:10.1029/2005GL024376 (2005).

14. Screen, J. A. Simulated atmospheric response to regional and Pan-Arctic sea-ice loss. $J$. Climate 30, https://doi.org/10.1175/JCLI-D-16-0197.1 (2017).

15. Liu, Y.\& Key, J. R. Assessment of Arctic cloud cover anomalies in atmospheric reanalysis products using satellite data. J. Climate 29, 6065-6083, https://doi:10.1175/JCLI-D-15-0861.1 (2016).

16. Lee, S. A theory for polar amplification from a general circulation perspective. Asia-Pac. J. Atmos. Sci. 50, 31-43, https://doi.org/10.1007/s13143-014-0024-7 (2014).

17. Park, H.-S., Lee, S., Son, S.-W., Feldstein, S. B. \& Kosaka, Y. The impact of poleward moisture and sensible heat flux on Arctic winter sea-ice variability. J. Climate 28, 5030-5040, https://doi:10.1175/JCLI-D-15-0074.1 (2015). 
18. Cohen, J., et al. Arctic change and possible influence on mid-latitude climate and weather. US CLIVAR Report 2018-1, 41pp, https://doi:10.5065/D6TH8KGW (2018).

19. Doyle, J. G., et al. Water vapor intrusions into the high Arctic during winter. Geophys. Res. Lett. 38, https://doi:10.1029/2011GL047493 (2011).

20. Kapsch, M.-L., Graversen, R. G., Tjernström, M. \& Bintanja, R. The effect of downwelling longwave and shortwave radiation on Arctic summer sea ice. J. Climate 29, 1143-1159, https://doi:10.1175/JCLI-D-15-0238.1 (2016).

21. Hegyi, B. M. \& Taylor, P. C. The unprecedented 2016-17 Arctic sea ice growth season: The crucial role of atmospheric rivers and longwave fluxes. Geophys. Res. Lett. 45, 5204-5212, https://doi.org/10.1029/2017GL076717 (2018).

22. Kapcsh, M.-L, Graversen R. G. \& Tjernstrom, M. Springtime atmospheric energy transport and the control of Arctic summer sea-ice extent. Nature Climate Change, 3,744-748 https://doi:10.1038/nclimate1884 (2013).

23. Yang, W. \& Magnusdottir, G. Springtime extreme moisture transport into the Arctic and its impact on sea ice concentration. J. Geophys. Res. Atmos. 122, 5516-5329, https://doi:10.1002/2016JD026324 (2017).

24. Yang, W. \& Magnusdottir, G. Year-to-year variability in Arctic minimum sea ice extent and its preconditions in observations and the CESM Large Ensemble simulations. Scientific Reports, https://doi.org/10.1038/s41598-018-27149-y (2018). 
25. Lee, S., Gong, T. T., Johnson, N. C., Feldstein, S. B. \& Pollard, D. On the possible link between tropical convection and the Northern Hemisphere Arctic surface air temperature change between 1958-2001. J. Climate 24, 4350-4367, https://doi.org/10.1175/2011JCLI4003.1 (2011).

26. Cvijanovic, I. et al. Future loss of Arctic sea-ice cover could drive a substantial decrease in California's rainfall. Nat. Comm., https://doi.org/10.1038/s41467-017-01907-4 (2017).

27. Lee, S. Testing of the tropically excited Arctic warming (TEAM) mechanism with traditional El Niño and La Niña. J. Climate 25, 4015-4022, https://doi.org/10.1175/JCLI-D-1200055.1 (2012).

28. Yoo, C., Lee, S. \& Feldstein, A. Arctic response to an MJO-like tropical heating in an idealized GCM. J. Atmos. Sci. 69, 2379-2393, https://doi.org/10.1175/JAS-D-11-0261.1 (2012a).

29. Yoo, C., Lee, S. \& Feldstein, S. B. Mechanisms of Arctic surface air temperature change in response to the Madden-Julian Oscillation. J. Climate 25, 5777-5790, https://doi.org/10.1175/JCLI-D-11-00566.1 (2012b).

30. Henderson, G. R., Barrett, B. S. \& LaFleur, D. M. Arctic sea ice and the Madden-Julian Oscillation (MJO). Climate Dyn. 43, 2185-2196, https://doi.org/10.1007/s00382-013-2043-y (2014).

31. Goss, M., Feldstein, S. B. \& Lee, S. Stationary wave interference, and its relation to tropical convection and Arctic warming. J. Climate 29, 1369-1389, https://doi.org/10.1175/JCLI-D-150267.1 (2016).

32. Honda, M., Inoue, J. \& Yamane, S. Influence of low Arctic sea-ice minima on anomalously cold Eurasian winters. Geophys. Res. Lett. 36, https://doi.org/10.1029/2008GL037079 (2009). 
33. Orsolini, Y., Senan, R., Benestad, R. E. \& Melsom, A. Autumn atmospheric response to the 2007 low Arctic sea ice extent in coupled ocean-atmosphere hindcasts. Climate Dyn. 38, 24372448, https://doi.org/10.1007/s00382-011-1169-z (2012).

34. Wegmann, M. et al. Arctic moisture source for Eurasian snow cover variations in autumn. Environ. Res. Lett. 10, https://doi.org/10.1088/1748-9326/10/5/054015 (2015).

35. Cohen, J., Furtado, J., Jones, J., Barlow, M., Whittleston, D. \& Entekhabi, D. Linking Siberian snow cover to precursors of stratospheric variability. J. Climate 27, 5422-5432 (2014).

36. Overland, J. E. et al. The melting Arctic and mid-latitude weather patterns: Are they connected? J. Climate 28, 7917-7932, https://doi.org/10.1175/JCLI-D-14-00822.1 (2015).

37. Zuo, J., Ren, H. L., Wu, B. \& Li, W. Predictability of winter temperature in China from previous autumn Arctic sea ice. Climate Dyn. 47, 2331, https://doi.org/10.1007/s00382-015-29666 (2016).

38. Overland, J. E. \& Wang, M. Arctic-midlatitude weather linkages in North America. Polar Sci. 16, 1-9, https://doi:10.1016/j.polar.2018.02.001 (2018).

39. Kug, J.-S. et al. Two distinct influences of Arctic warming on cold winters over North America and East Asia. Nat. Geosci. 8, 759-762, https://doi.org/10.1038/ngeo2517 (2015).

40. Lee, M.-Y., Hong, C.-C. \& Hsu, H.-H. Compounding effects of warm sea surface temperature and reduced sea ice on the extreme circulation over the extratropical North Pacific and North America during the 2013-2014 boreal winter. Geophys. Res. Lett. 42, 1612-1618, https://doi.org/10.1002/2014GL062956 (2015). 
41. Cohen, J. An observational analysis: Tropical relative to Arctic influence on midlatitude weather in the era of Arctic amplification. Geophys. Res. Lett. 43, 5287-5294, https://doi.org/10.1002/2016GL069102 (2016).

42. Baxter, S. \& Nigam, S. Key role of North Pacific oscillation/West Pacific pattern in generating the extreme 2013-2014 North American winter. J. Climate 28, 8109-8117, https://doi.org/10.1175/JCLI-D-14-00726.1 (2015).

43. Ding, Q. et al. Tropical forcing of the recent rapid Arctic warming in northeastern Canada and Greenland. Nature 509, 209-212, https://doi.org/10.1038/nature13260 (2014).

44. Sun, L., Perlwitz, J. \& Hoerling, M. What caused the recent "Warm Arctic, Cold Continents" trend pattern in winter temperatures? Geophys. Res. Lett. 43, 5345-5352 (2016).

45. Ballinger, T. et al. Greenland coastal air temperatures linked to Baffin Bay and Greenland Sea ice conditions during autumn through regional blocking patterns. Climate Dyn. 50, 83-100, https://doi.org/10.1007/s00382-017-3583-3 (2018).

46. Chen, X. \& Luo, D. Arctic sea ice decline and continental cold anomalies: Upstream and downstream effects of Greenland blocking. Geophys. Res. Lett. 44, 3411-3419, https://doi.org/10.1002/2016GL072387 (2017).

47. Woollings, T., Hannachi, A. \& Hoskins, B. Variability of the North Atlantic eddy-driven jet stream. Quart. J. Roy. Meteor. Soc. 136, 856-868, https://doi.org/10.1002/qj.625 (2010).

48. Petoukhov, V. \& Semenov, V. A link between reduced Barents-Kara sea ice and cold winter extremes over northern continents. J. Geophys. Res. 115, https://doi.org/10.1029/2009JD013568 (2010). 
49. Liptak, J. \& Strong, C. The winter atmospheric response to sea ice anomalies in the Barents Sea. J. Climate 27, 914-924, https://doi.org/10.1175/JCLI-D-13-00186.1 (2014).

50. Sun, L., Deser, C. \& Tomas, R. A. Mechanisms of stratospheric and tropospheric circulation response to projected Arctic sea ice loss. J. Climate 28, 7824-7845, https://doi.org/10.1175/JCLI-D-15-0169.1 (2015).

51. Peings, Y. \& Magnusdottir, G. Response of the wintertime Northern Hemisphere atmospheric circulation to current and projected Arctic sea ice decline: A numerical study with CAM5. J. Climate 27, 244-264, https://doi.org/10.1175/JCLI-D-13-00272.1 (2014).

52. Semenov V. A. \& Latif, M. Nonlinear winter atmospheric circulation response to Arctic sea ice concentration anomalies for different periods during 1966-2012. Environ. Res. Lett. 10(5), 054020, https://doi.org/10.1088/1748-9326/10/5/054020 (2015).

53. Chen, H. W., Zhang, F. \& Alley, R. B. The robustness of midlatitude weather pattern changes due to Arctic sea ice loss. J. Climate 29, 7831-7849, https://doi.org/10.1175/JCLI-D-16$0167.1(2016)$.

54. Overland, J. E., Francis, J. A., Hanna, E. \& Wang, M. The recent shift in early summer Arctic atmospheric circulation. Geophys. Res. Lett. 39, L19804, https://doi.org/10.1029/2012GL053268 (2012).

55. Coumou, D., Petoukhov, V., Rahmstorf, S., Petri, S. \& Schellnhuber, H. J. Quasi-resonant circulation regimes and hemispheric synchronization of extreme weather in boreal summer. Proc. Nat. Acad. Sci. 111, 12331-12336, https://doi.org/10.1073/pnas.1412797111 (2014). 
56. Coumou, D., Lehmann, J. \& Beckmann, J. The weakening summer circulation in the Northern Hemisphere mid-latitudes. Science 348, 324-327, https://doi.org/10.1126/science.1261768 (2015).

57. Lehmann, J., Coumou, D., Frieler, K., Eliseev, A. V. \& Levermann, A. Future changes in extratropical storm tracks and baroclinicity under climate change. Environ. Res. Lett. 9, https://doi.org/10.1088/1748-9326/9/8/084002 (2014).

58. Chang, E. K. M., Ma, C.-G., Zheng, C. \& Yau, A. M. W. Observed and projected decrease in Northern Hemisphere extratropical cyclone activity in summer and its impacts on maximum temperature. Geophys. Res. Lett. 43, 2200-2208, https://doi:10.1002/2016GL068172 (2016).

59. Coumou, D., Kornhuber, K., Lehmann, J. \& Petoukhov, V. Weakened flow, persistent circulation, and prolonged weather extremes in boreal summer. Climate Extremes: Patterns and Mechanisms, Geophys. Monogr. 226, S.-Y. Wang, J.-H. Yoon, C. C. Funk, and R. R. Gilles, Eds., Amer. Geophys. Union, 61-74, ISBN:978119067849 (2017).

60. Coumou, D., Di Capua, G., Vavrus, S., Wang, L. \& Wang, S. The influence of Arctic Amplification on mid-latitude summer circulation. Nat. Comm. (2018 in revision).

61. Blackport, R., Screen, J. A., van der Wiel, K. \& Bintanja, R. Minimal influence of reduced Arctic sea ice on coincident cold winters in mid-latitudes. Nature Climate Change 9, 697-704, https://doi.org/10.1038/s41558-019-0551-4 (2019).

62. Wendisch, M. et al. Understanding causes and effects of rapid warming in the Arctic. Eos 98, https://doi.org/10.1029/2017EO064803 (2017). 
63. Morice, C. P., Kennedy, J. J., Rayner, N. A. \& Jones, P. D. Quantifying uncertainties in global and regional temperature change using an ensemble of observational estimates: the HadCRUT4 dataset. J. Geophys. Res. 117, D08101, https://doi:10.1029/2011JD017187 (2012). 